\title{
Natural antisense transcripts in the biological hallmarks of cancer: powerful regulators hidden in the dark
}

\author{
Shanshan Zhao ${ }^{1}$, Xue Zhang ${ }^{2}$, Shuo Chen $^{3}$ and Song Zhang ${ }^{4,5^{*}}$
}

\begin{abstract}
Natural antisense transcripts (NATs), which are transcribed from opposite strands of DNA with partial or complete overlap, affect multiple stages of gene expression, from epigenetic to post-translational modifications. NATs are dysregulated in various types of cancer, and an increasing number of studies focusing on NATs as pivotal regulators of the hallmarks of cancer and as promising candidates for cancer therapy are just beginning to unravel the mystery. Here, we summarize the existing knowledge on NATs to highlight their underlying mechanisms of functions in cancer biology, discuss their potential roles in therapeutic application, and explore future research directions.
\end{abstract}

Keywords: Natural antisense transcripts, NATs, Cancer, Hallmarks of cancer

\section{Background}

High-throughput RNA sequencing has revealed the universal transcriptional information of the human genome, of which non-coding sequences account for 98\% [1]. Non-coding sequences were previously considered as "junk DNA" due to their low expression levels, unknown functions, and heterogeneity [2, 3]. However, mounting evidence has demonstrated that non-coding RNAs (ncRNAs) can modulate the expression of proteincoding RNA and play indispensable roles in various biological processes, including tumorigenesis, metastasis, and therapeutic resistance [4-7].

ncRNAs are classified into two groups based on the transcript length. In general, 200 nucleotides is used as the biophysical threshold for separating long ncRNAs (lncRNAs) from short ncRNAs. The lncRNAs are further divided into different subclasses, and include intronic

\footnotetext{
*Correspondence: cmuzs93@163.com

${ }^{4}$ Department of Thoracic Surgery, The First Affiliated Hospital of China Medical University, 110001 Shenyang, Liaoning, China

${ }^{5}$ Department of Environmental and Occupational Health, School of Public Health, China Medical University, 110122 Shenyang, Liaoning, China

Full list of author information is available at the end of the article
}

lncRNAs, bidirectional lncRNAs, intergenic lncRNAs, enhancer RNAs, circular RNAs (circRNAs), pseudogenes, sense lncRNAs, and natural antisense transcripts (NATs), based on their original genomic locations or their relationships with protein-coding genes. For more details on lncRNAs classification, please refer to $[8,9]$.

NATs are RNA molecules transcribed from the opposite strands of DNA that partially or completely overlap with the sense RNA $[10,11]$. Investigations of NATs have been initiated in recent years due to the development of high-throughput sequencing, and NATs have attracted increasing interest due to their significant roles in diverse pathophysiological processes [11]. Many NATs were first annotated as lncRNAs, and therefore described as a subclass of lncRNA [12, 13]. Even so, NATs can also be short ncRNAs $[11,14]$ or proteincoding genes [15]. The incomplete overlap between the classification of NATs and lncRNAs may be confusing. Therefore, it is necessary to understand the generation and intrinsic characteristics of NATs before investigating their potential mechanisms and functions. 
NATs can be produced from shared bidirectional promoters (i.e., when the transcription start sites (TSS) of a NAT and its sense counterpart are separated by $\leq 1 \mathrm{~kb}$ [16]), independent, or latent promoters found within genes (i.e., when the NAT TSS is entirely covered by its sense counterpart [17]). The expression of NAT is also regulated by promoters and enhancers [12, 17]. Furthermore, NATs can be capped, poly-adenylated and undergo intron excision, much like the maturation process of mRNAs [18]. Based on the orientation with reference to sense genes, NATs can be divided into three categories: (1) head-to-head (5' -regions overlap), (2) tail-to-tail (3' -regions overlap), and (3) embedded (one transcript is completely incorporated within the other) [17].

NATs can also be divided into cis-NATs, transcribed from the same genomic loci on different strands with perfect RNA-RNA sequence complementarity, and trans-NATs, transcribed from different genomic loci with imperfect sequence complementarity (Fig. 1) [10, 19].

Functionally, NATs participate in multiple processes of gene expression regulation, from controlling epigenetic modifications to modulating post-transcriptional modifications $[11,20]$. Aberrant expression of NATs is associated with human disease pathology, including cancer [21]. The purpose of this review is to classify the molecular mechanisms of NATs in cancer and their roles in tumorigenesis and progression.

\section{Introduction to NATs in cancer}

The term cancer refers to a group of genetic diseases, in which cell signaling networks are modified, resulting in disorganized cell homeostasis and uncontrolled growth $[22,23]$. As non-coding DNA accounts for $98 \%$ of the genome, it seems inevitable that aberration in the noncoding genome serves a role in regulating the phenotypes of cancer [2]. Accumulating evidence has demonstrated that NATs act as biomarkers for cellular pathophysiologies, provide diagnostic and prognostic value, and reveal promising therapeutic targets for cancer $[11,12]$. For example, as a classic oncogenic NAT, HOTAIR is situated in the HOXC locus and transcribed from the antisense strand [24, 25]. HOTAIR supports tumor-cell stemness, proliferation and metastasis, as well as therapeutic resistance in 26 human tumor types, by interacting with molecules such as miRNAs, ubiquitin ligases, and chromatin modifiers [26-32]. Additionally, HOXA11-AS, the homeobox A11 antisense transcript, acts as an initiator of tumorigenesis and metastasis through epigenetic modifications in the nucleus or as an miRNA sponge (RNA molecules that act as competing endogenous RNAs (ceRNAs) by binding to miRNAs, thereby reducing the regulatory effects of miRNAs on target mRNAs, subsequently improving mRNA stability and protein expression [33]) in the cytoplasm [34].

NATs may also participate in tumorigenesis and progression via interplay with paired sense RNA in cis and/ or in trans. ZEB1-AS1, which is transcribed from the antisense strand of the ZEB1 locus, correlates positively with ZEB1 expression and promotes multiple malignant phenotypes in numerous malignancies [35-42]. ZEB1AS1 can bind and recruit histone methyltransferase MLL1 or histone acetyltransferase p300 to the ZEB1 promoter region, activating ZEB1 transcription epigenetically, thereby acting as an oncogene in cis [41, 43]. ZEB1-AS1 can also facilitate colon adenocarcinoma progression in trans by sponging miR-455-3p to upregulate PAK2, which is tightly associated with tumor cell proliferation, invasion, and apoptosis [44-46]. These are just introductions to NATs in cancer; the following sections will provide more detail.

\section{Molecular mechanisms of NAT activity}

Different subcellular localizations of NATs bring about different mechanisms of biological functions. NATs accumulated in the nucleus are mainly involved in epigenetic modifications, transcriptional interference,

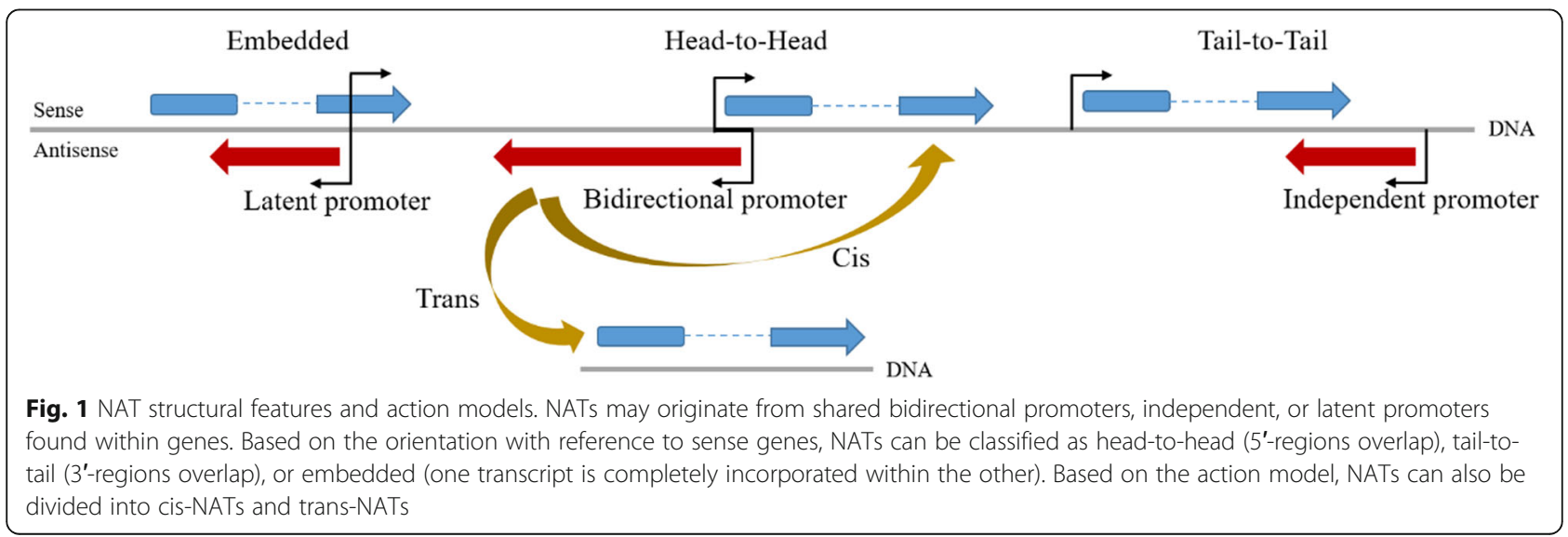


alternative splicing, and RNA processing. Whereas cytoplasmic NATs mainly regulate RNA stability and/or mRNA translatability $[2,11]$. Therefore, we have divided NATs into nuclear NATs and cytoplasmic NATs (Table 1). Each category will be discussed in detail below.

\section{Epigenetic modifications}

NATs can control transcription initiation via histone modifications, which mainly consist of methylation and acetylation, or methylation in the CpG islands of the promoter [11, 47]. A classic example of NAT-mediated histone modification is HOTAIR. Mechanically, the $5^{\prime}$ region of HOTAIR recruits PRC2, an epigenetic silencer of target genes that catalyzes the trimethylation of histone $\mathrm{H} 3$ lysine 27 (H3K27me3), facilitating epigenetic gene silencing [48].

Moreover, the 3 '-region of HOTAIR can also recruit another chromatin regulator, LSD1, a histone demethylase that triggers histone $\mathrm{H} 3$ lysine $\mathrm{K} 4$ demethylation and acts as a histone mark for gene repression [49]. Therefore, HOTAIR can function as a bifunctional regulatory RNA or a molecular "scaffold" to alter the chromatin state, leading to transcription repression and epigenetic silencing of the target genes [48, 50] (Fig. 2a). Taken together, this evidence proposes a model in which NATs facilitate recruitment of chromatin-modifying complexes when located at the appropriate sites.

NATs also play potential roles in mediating gene activation. It has been suggested that NATs can function as a "local address code" and thus establish a DNA-RNA triplex structure with target chromatin-modifying enzymes at specific gene sequences [41]. For example, KHPS1, which is transcribed from the antisense strand of proto-oncogene SPHK1, can form an RNA-DNA triplex at the SPHK1 enhancer. This triplex then recruits CBP/p300 to the SPHK1 promoter. CBP and p300 are closely related histone acetyltransferases (HATs) that act together as a cis-regulatory element to increase H3K27ac (histone H3 lysine 27 acetylation) levels on the enhancer and the promoter of its target gene, thereby activating gene expression through interacting with various transcription factors. In this way, the NAT KHPS1 results in local modifications of chromatin structure, which stimulates the binding of transcription factor E2F1 and promoting transcription [51].

In addition to mediating histone modifications, NATs have been shown to shape DNA methylation patterns. As a tumor suppressor gene, PTEN is mutated and epigenetically silenced in various cancer types [52-55]. The antisense transcript of PTEN can recruit DNA methyltransferase 3a (DNMT3a) to the PTEN promoter, leading to chromatin condensation and ultimately epigenetic and transcriptional suppression of PTEN expression [56] (Fig. 2b).

\section{Transcriptional interference}

Antisense transcription can modulate the expression of sense transcript through transcriptional interference [12], in which one transcriptional process exerts a suppressive effect on another in cis and directly $[57,58]$.

Antisense-mediated transcriptional interference may take place not only in transcription initiation but also in transcription elongation, and several theoretical models have been established by Shearwin and colleagues to enlighten the underlying mechanisms: (A) Promoter competition, occupation of RNA polymerase (RNAP) by the antisense promoter inhibits its occupation by the sense promoter, thus downregulating both transcripts; (B) Dislodgement, the sense promoter is sensitive to RNAP binding, but slow to initiate, and thus be dislodged by the antisense RNAP complex; (C) Occlusion, the sense promoter is occluded by the RNAP complex during elongation of the antisense transcript; (D) Collision, a collision between RNAP complexes in the overlapping region of the sense and antisense genes blocks further transcriptions, and (E) Roadblock, RNAP bound to the antisense promoter blocks the progress of the RNAP complex from the sense promoter. The first 3 of these models may participate in the transcription initiation phase of sense genes, and the final 2 in the elongation phase (Fig. 3). For more details, please refer to [58]. However, it is unlikely that transcriptional interference can be fully explained by such simple models. The sophistication of chromatin structure and the diversity of transcription initiation complexes pose challenges for studying transcriptional interference in higher eukaryotes.

Nevertheless, accumulating evidence has demonstrated that NATs can regulate transcriptional interference. AIRN is the antisense noncoding RNA of IGF2R, an imprinted tumor suppressor [59, 60]. AIRN can suppress the expression of the IGF2R promoter. Further studies have revealed that the transcriptional overlap between AIRN and the IGF2R promoter silences IGF2R, rather than the AIRN products, indicating the involvement of AIRN in transcriptional interference [59]. Another example is GNG12-AS, which is transcribed in an antisense orientation to the tumor-suppressor DIRAS3. In this case, GNG12-AS, preferentially localized in the nucleus, can be transcriptionally silenced via a specific siRNA (which can exert regulatory effects on transcription in the nucleus in the presence of AGO2 [61, 62]) complementary to GNG12-AS1 exon 1, which is adjacent to the TSS. Mechanistically, the specific siRNA can form a regulatory complex with AGO2 and GNG12-AS1 at the GNG12-AS1 TSS to inhibit RNAP recruitment, leading to the repression of transcription initiation and elongation of GNG12-AS1. In contrast, a concomitant increase in RNAP recruitment is observed at 
Table 1 NATs in the hallmarks of cancer

\begin{tabular}{|c|c|c|c|c|c|}
\hline NAT & $\begin{array}{l}\text { Preferential } \\
\text { localization }\end{array}$ & Cancer type & Mechanism & Hallmark & Ref. \\
\hline HOTAIR & $\begin{array}{l}\text { Nucleus/ } \\
\text { cytoplasm }\end{array}$ & Various types & $\begin{array}{l}\text { Epigenetic modifications } \\
\text { miRNA sponge } \\
\text { PTM }\end{array}$ & $\begin{array}{l}\text { Resistance to cell death } \\
\text { Activation of invasion and } \\
\text { metastasis } \\
\text { Genome instability and mutation } \\
\text { Tumor-promoting inflammation }\end{array}$ & $\begin{array}{l}{[29,31,125,} \\
165]\end{array}$ \\
\hline $\begin{array}{l}\text { HOXA11- } \\
\text { AS }\end{array}$ & $\begin{array}{l}\text { Nucleus/ } \\
\text { cytoplasm }\end{array}$ & Various types & $\begin{array}{l}\text { Epigenetic modifications } \\
\text { miRNA sponge }\end{array}$ & $\begin{array}{l}\text { Sustaining proliferative signaling } \\
\text { Activation of invasion and } \\
\text { metastasis } \\
\text { Tumor-promoting inflammation }\end{array}$ & $\begin{array}{l}{[34,168,} \\
187]\end{array}$ \\
\hline ZEB1-AS1 & $\begin{array}{l}\text { Nucleus/ } \\
\text { cytoplasm }\end{array}$ & Various types & $\begin{array}{l}\text { Epigenetic modifications } \\
\text { miRNA sponge }\end{array}$ & $\begin{array}{l}\text { Sustaining proliferative signaling } \\
\text { Resistance to cell death } \\
\text { Activation of invasion and } \\
\text { metastasis }\end{array}$ & {$[40,42,46]$} \\
\hline KHPS1 & Nucleus & Various types & Epigenetic modification & $\begin{array}{l}\text { Resistance to cell death } \\
\text { Tumor-promoting inflammation } \\
\text { Reprogramming energy } \\
\text { metabolism }\end{array}$ & $\begin{array}{l}{[51,188,} \\
189]\end{array}$ \\
\hline $\begin{array}{l}\text { NAT of } \\
\text { PTEN }\end{array}$ & Nucleus & Various types & Epigenetic modification & Evasion of growth suppressors & [56] \\
\hline AIRN & Nucleus & Various types & Transcriptional interference & Evasion of growth suppressors & {$[59,60,190]$} \\
\hline $\begin{array}{l}\text { GNG12- } \\
\text { AS }\end{array}$ & Nucleus & Breast cancer & Transcriptional interference & $\begin{array}{l}\text { Resistance to cell death } \\
\text { Activation of invasion and } \\
\text { metastasis }\end{array}$ & [63] \\
\hline EGOT & Nucleus & Breast cancer & Alternative splicing & Resistance to cell death & [67] \\
\hline ZEB2-AS1 & $\begin{array}{l}\text { Nucleus/ } \\
\text { cytoplasm }\end{array}$ & Various types & $\begin{array}{l}\text { Alternative splicing } \\
\text { promotes mRNA stability and } \\
\text { translatability } \\
\text { PTM }\end{array}$ & $\begin{array}{l}\text { Sustaining proliferative signaling } \\
\text { Activation of invasion and } \\
\text { metastasis }\end{array}$ & {$[68,69,191]$} \\
\hline PCA3 & Nucleus & Prostate cancer & RNA editing & Evasion of growth suppressors & [71] \\
\hline $\begin{array}{l}\text { HIF1A- } \\
\text { AS2 }\end{array}$ & $\begin{array}{l}\text { Nucleus/ } \\
\text { cytoplasm }\end{array}$ & Various types & $\begin{array}{l}\text { RNA editing } \\
\text { miRNA sponge }\end{array}$ & $\begin{array}{l}\text { Induction of angiogenesis } \\
\text { Tumor-promoting inflammation } \\
\text { Reprogramming energy } \\
\text { metabolism }\end{array}$ & $\begin{array}{l}{[74,136,} \\
137]\end{array}$ \\
\hline GLS-AS & Cytoplasm & Pancreatic cancer & RNAi & $\begin{array}{l}\text { Sustaining proliferative signaling } \\
\text { Activation of invasion and } \\
\text { metastasis } \\
\text { Reprogramming energy } \\
\text { metabolism }\end{array}$ & [80] \\
\hline $\begin{array}{l}\text { PDCD4- } \\
\text { AS1 }\end{array}$ & Nucleus & Breast cancer & promotes mRNA stability & $\begin{array}{l}\text { Activation of invasion and } \\
\text { metastasis }\end{array}$ & [82] \\
\hline KRT7-AS1 & Nucleus & Gastric cancer & promotes mRNA stability & $\begin{array}{l}\text { Sustaining proliferative signaling } \\
\text { Activation of invasion and } \\
\text { metastasis }\end{array}$ & [83] \\
\hline DHPS & $\begin{array}{l}\text { Nucleus/ } \\
\text { cytoplasm }\end{array}$ & Gastric cancer & promotes mRNA stability & Sustaining proliferative signaling & [15] \\
\hline $\begin{array}{l}\text { NAT of } \\
\text { BCMA }\end{array}$ & Cytoplasm & Mlultiple myeloma & Translational interference & $\begin{array}{l}\text { Resistance to cell death } \\
\text { Tumor-promoting inflammation }\end{array}$ & {$[84,192]$} \\
\hline $\begin{array}{l}\text { NAT of } \\
\text { PU.1 }\end{array}$ & Cytoplasm & Leukemia & Translational interference & Enabling replicative immortality & {$[86,193]$} \\
\hline ZFAS1 & $\begin{array}{l}\text { Nucleus/ } \\
\text { cytoplasm }\end{array}$ & Osteosarcoma,colorectal cancer & $\begin{array}{l}\text { Epigenetic modification } \\
\text { miRNA sponge }\end{array}$ & $\begin{array}{l}\text { Sustaining proliferative signaling } \\
\text { Activation of invasion and } \\
\text { metastasis } \\
\text { Induction of angiogenesis }\end{array}$ & {$[89,139]$} \\
\hline SOX9-AS1 & Cytoplasm & Hepatocellular carcinoma & miRNA sponge & $\begin{array}{l}\text { Sustaining proliferative signaling } \\
\text { Activation of invasion and } \\
\text { metastasis }\end{array}$ & [90] \\
\hline ASB16- & Cytoplasm & Gastric cancer & PTM & Sustaining proliferative signaling & [95] \\
\hline
\end{tabular}


Table 1 NATs in the hallmarks of cancer (Continued)

\begin{tabular}{|c|c|c|c|c|c|}
\hline NAT & $\begin{array}{l}\text { Preferential } \\
\text { localization }\end{array}$ & Cancer type & Mechanism & Hallmark & Ref. \\
\hline AS1 & & & & Resistance to cell death & \\
\hline $\begin{array}{l}\text { RHPN1- } \\
\text { AS1 }\end{array}$ & Cytoplasm & Cervical cancer & miRNA sponge & $\begin{array}{l}\text { Activation of invasion and } \\
\text { metastasis }\end{array}$ & [104] \\
\hline MYLK-AS1 & Cytoplasm & Hepatocellular carcinoma & PTM & $\begin{array}{l}\text { Sustaining proliferative signaling } \\
\text { Activation of invasion and } \\
\text { metastasis }\end{array}$ & [105] \\
\hline PANDAR & Nucleus & Ovarian cancer & $\begin{array}{l}\text { Alternative splicing } \\
\text { PTM }\end{array}$ & Evasion of growth suppressors & [109] \\
\hline WRAP53a & $\begin{array}{l}\text { Nucleus/ } \\
\text { cytoplasm }\end{array}$ & Breast cancer & promotes mRNA stability & $\begin{array}{l}\text { Evasion of growth suppressors } \\
\text { Resistance to cell death }\end{array}$ & [110] \\
\hline $\begin{array}{l}\text { FOXD2- } \\
\text { AS1 }\end{array}$ & Cytoplasm & Thyroid cancer & miRNA sponge & Enabling replicative immortality & [113] \\
\hline TP73-AS1 & Nucleus & $\begin{array}{l}\text { Clear cell renal cell carcinoma, } \\
\text { ovarian cancer }\end{array}$ & Epigenetic modification & $\begin{array}{l}\text { Resistance to cell death } \\
\text { Activation of invasion and } \\
\text { metastasis }\end{array}$ & {$[120,129]$} \\
\hline HAGLROS & Cytoplasm & Colorectal cancer & $\begin{array}{l}\text { miRNA sponge } \\
\text { PTM }\end{array}$ & Resistance to cell death & [121] \\
\hline $\begin{array}{l}\text { HOXD- } \\
\text { AS1 }\end{array}$ & Cytoplasm & Lung cancer & miRNA sponge & $\begin{array}{l}\text { Sustaining proliferative signaling } \\
\text { Activation of invasion and } \\
\text { metastasis }\end{array}$ & [128] \\
\hline $\begin{array}{l}\text { RAD51- } \\
\text { AS1 }\end{array}$ & Cytoplasm & Hepatocellular carcinoma & Translational interference & Genome instability and mutation & {$[145]$} \\
\hline WRAP53ß & Cytoplasm & Various types & PTM & Genome instability and mutation & {$[167]$} \\
\hline SIRT1-AS & Cytoplasm & Hepatocellular carcinoma & miRNA sponge & $\begin{array}{l}\text { Activation of invasion and } \\
\text { metastasis } \\
\text { Genome instability and mutation }\end{array}$ & [151] \\
\hline $\begin{array}{l}\text { NKX2-1- } \\
\text { AS1 }\end{array}$ & Nucleus & Lung cancer & Binding decoy & $\begin{array}{l}\text { Avoidance of immune detection } \\
\text { and destruction }\end{array}$ & [154] \\
\hline ITIH4-AS1 & Cytoplasm & Colorectal cancer & PTM & Tumor-promoting inflammation & [169] \\
\hline IDH1-AS1 & Cytoplasm & Cervical cancer & Physical interference & $\begin{array}{l}\text { Reprogramming energy } \\
\text { metabolism }\end{array}$ & {$[176]$} \\
\hline
\end{tabular}

the DIRAS3 TSS, followed by the overexpression of DIRAS3 [63], suggesting the promoter competition model of transcriptional interference.

\section{NATs mediate alternative splicing}

Alternative splicing is a process by which a single gene can produce multiple protein isoforms that may exert different or even opposite functions on biological behaviors [64]. Classically, NATs participate in the regulation of alternative splicing by interacting with specific splicing factors [65]. EGOT is an antisense ncRNA transcribed from sense ITPR1, which induces autophagy and sensitizes breast cancer cells to paclitaxel (an anticancer agent that prevents mitosis and inhibits cancer cell proliferation [66]). EGOT can recruit a splicing factor, hnRNPH1, through specific motifs and bind to the ITPR1 pre-mRNA to regulate the alternative splicing of pre-ITPR1, thereby leading to ITPR1 overexpression. In this manner, EGOT acts as an oncogene [67].
In addition, NAT can directly disrupt the balance among splicing variants by forming an RNA-RNA duplex with its sense RNA to mask splicing sites [11]. A well-known example is ZEB2-AS1, the NAT of ZEB2. ZEB2 is a transcription factor that participates in cancer complexity and functions as a biomarker for endothelial-mesenchymal transition (EMT). ZEB2-AS1 overlaps with the 5' UTR (untranslated region) intron of ZEB2, which contains an internal ribosome entry site (IRES) necessary for ZEB2 translation, thereby forming an RNA-RNA duplex to protect the IRES from processing, and consequently enhancing the translation efficiency of ZEB2 [68]. This is thought to drive EMT in various cancers [69].

NATs can also affect alternative splicing by fine-tuning chromatin signatures. A nuclear antisense lncRNA, transcribed from the FGFR2 locus, recruits polycomb-related proteins and KDM2a, a histone demethylase, to the FGFR2 locus, leading to chromatin remodeling, thereby 


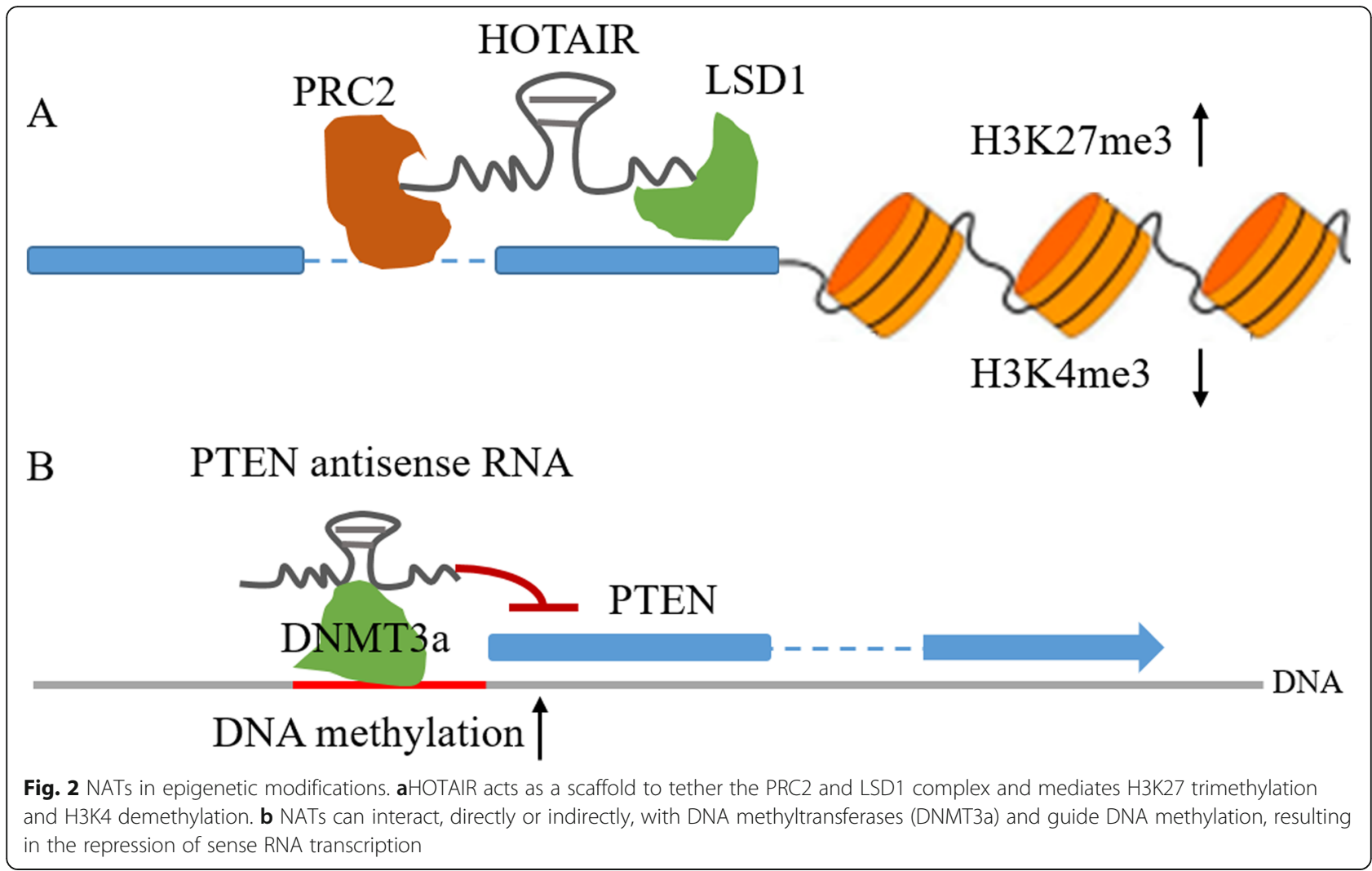

preventing the binding of a chromatin-splicing adaptor complex necessary for FGFR2 splicing [70].

\section{NATs mediate sense RNA editing}

RNA editing is a widespread post-transcriptional mechanism by which specific nucleotides in an RNA sequence are modified. Adenosine deaminases that act on RNA (ADAR) proteins are key regulatory enzymes responsible for adenosine-to-inosine (A-to-I) RNA editing in doublestranded RNA (dsRNA) molecules, which is the most common pattern of RNA editing in humans [71]. Such modifications may be dysregulated in cancer, and alter the expression of the edited transcript [72, 73]. Notably, nuclear NATs commonly form dsRNA structures with their sense counterparts. Identifying the occurrence frequency of RNA editing by NATs might be ambitious, but it would be a worthwhile exploration. Indeed, some NATs have been implicated in A-to-I RNA editing.

PCA3 is an antisense lncRNA transcribed from intron 6 of the PRUNE2 gene, which acts as a tumor suppressor in prostate cancer. PCA3 can bind PRUNE2 premRNA to form a PRUNE2/PCA3 dsRNA structure, which undergoes adenosine ADAR-dependent A-to-I RNA editing, leading to decreased expression of PRUNE2 and increased tumor cell proliferation [71]. Another interesting example of RNA editing by NATs is HIF1A-AS2. Full-length HIF1A-AS2 itself can form multiple RNA editing-favoring dsRNA structures, therefore it is a promising substrate of RNA editing. Further examinations have validated the fact that HIF1A-AS2 undergoes A-to-I editing mediated by ADAR1, an essential member of the ADAR family [74].

NATs mediate mRNA stability, translatability, and posttranslational modifications

As regulators that can be found in almost every biological process, NATs also exert effects on mRNA stability, translatability, and post-translational modifications (PTMs) [75].

In general, human NATs can form RNA duplexes with their sense partners to regulate sense mRNA stability by directly masking specific sequences that could otherwise facilitate mRNA degradation [76]. Specifically, antisense/ sense RNA duplex can regulate mRNA degradation by interacting with an RNA interference (RNAi) mediator, an RNA decay-promoting factor, or the RNase digestion machinery. As a critical component of the RNAi machinery, DICER induces gene silencing either via RNA cleavage or translational suppression [77]. ADAR1, a regulator of dsRNA molecules, distinguishes its function in RNAi from RNA editing by forming an ADAR1-DICE $\mathrm{R}$ heterodimer complex [78]. GLS is an imprinted oncogene that can stabilize c-MYC, another well-defined oncogene [79]. In addition, the intronic antisense 


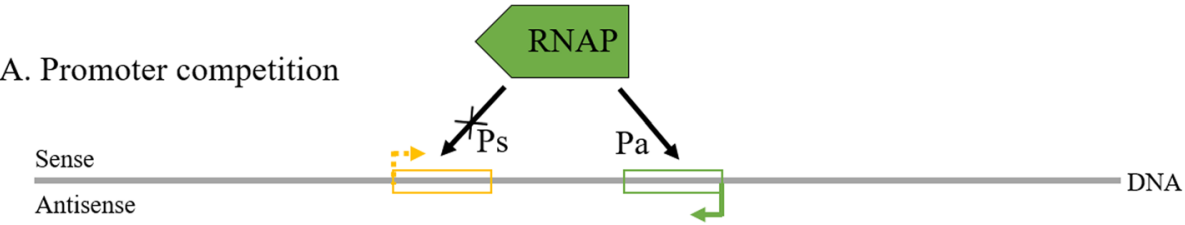

B. Dislodgement
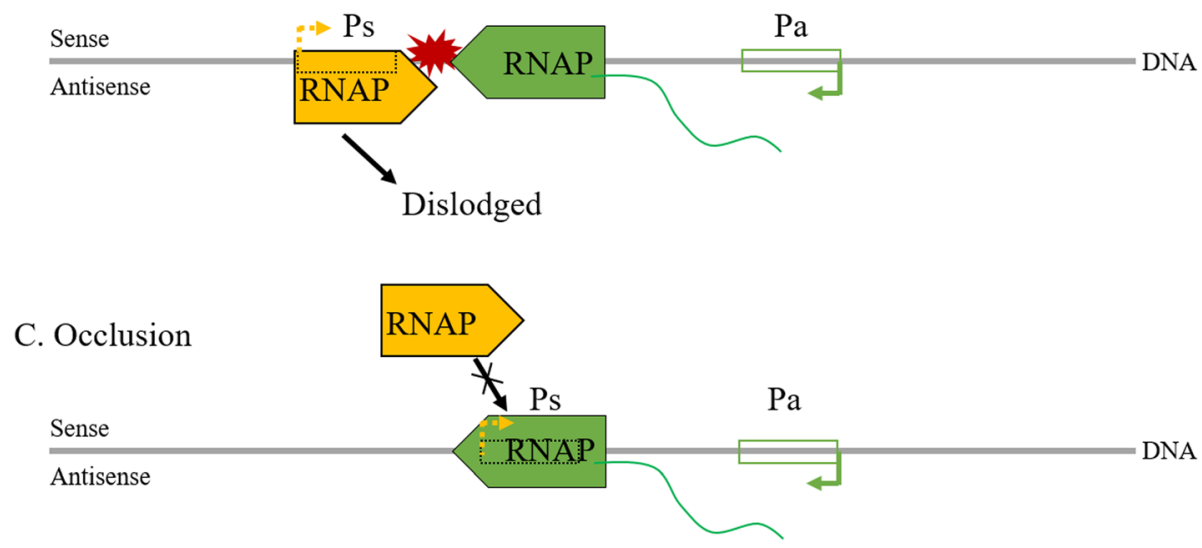

D. Collision

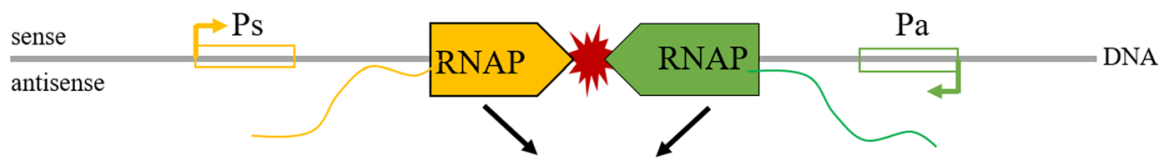

E. Roadblock

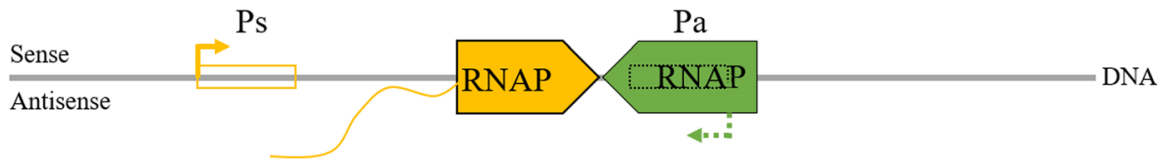

Fig. 3 NATs in transcriptional interference. In the initiation phase: a Promoter competition, the promoters of sense and antisense genes compete for RNAP complex; b Dislodgement, the RNAP complex of the sense gene promoter is dislodged by the arrival of the antisense gene RNAP complex; $\mathbf{c}$ Occlusion, the promoter of the sense gene is occluded by the antisense RNAP complex during antisense transcript elongation. In the elongation phase: $\mathbf{d}$ Collision, RNAP complexes collide in the overlapping region of the sense and antisense genes, blocking further transcriptions; e Roadblock, the antisense gene RNAP complex blocks that of the sense gene promoter. Ps, promoter of sense gene; Pa: promoter of antisense gene

transcript of GLS (GLS-AS) can form an RNA duplex with the sense GLS pre-mRNA, which further inhibits the expression of GLS through ADAR1/DICERdependent RNA degradation and leads to c-MYC downregulation [80]. An example of an RNA decaypromoting factor is $\mathrm{HuR}$, which acts as a powerful regulator of mRNA stability by binding to specific motifs at the UTRs of target mRNAs [81], including PDCD4. PDCD4 and its NAT partner, PDCD4-AS1, suppress breast cancer progression collaboratively. Mechanistically, PDCD4-AS1 prevents the interaction between PDCD4 mRNA and HuR in the nucleus by forming an RNA duplex with PDCD4, stabilizing PDCD4 mRNA and inhibiting malignant phenotypes [82]. Lastly, singlestranded RNA is susceptible to RNase digestion, while the antisense-sense RNA duplex may have a physical protective effect against RNase degradation, consequently gaining mutual stability [75]. In gastric cancer, the lncRNA KRT7-AS1 forms an embedded RNA duplex with its oncogenic sense gene, KRT7, at the exon adjacent to the poly(A) tail, increasing KRT7 mRNA stability and protein expression by protecting it from RNase degradation, consequently promoting tumor cell proliferation and migration [83]. Despite non-coding/proteincoding pairing, a similar mechanism can also be observed in protein-coding/protein-coding pairing. DHPS, 
a protein-coding NAT of WDR83 mRNA, forms a protective tail-to-tail RNA duplex with WDR83 at the 3' UTR to enhance mutual stability [15].

Besides, the antisense/sense RNA duplex can directly regulate protein translation through translational interference. For example, BCMA mRNA overlaps with its antisense transcript at the coding sequences. Overexpression of the BCMA NAT significantly decreases BCMA protein levels without changing BCMA RNA levels, indicating that BCMA NAT regulates BCMA expression mainly at translational level $[84,85]$. Another example of translational interference by NAT is the antisense transcript of PU.1, which clarifies the underlying mechanism. PU.1 (also known as Spi-1 proto-oncogene) overlaps with its antisense partner at the coding region. PU.1 NAT negatively modulates the expression of PU.1 protein without downregulating of PU.1 mRNA levels. Further efforts have shown that the overlapping coding region may interfere with the interaction between PU.1 mRNA and eEF1A (which promotes protein biosynthesis) [86, 87].

Based on the above findings, we note that the duplexes implicated in mRNA stability are adjacent to or just at the non-coding sequences of sense mRNAs, while the duplexes, which regulate translational interference, are located at the coding regions. Therefore, we propose the preliminary hypothesis that RNA-RNA duplexes may alter the secondary or tertiary structure of mRNA, thereby affecting mRNA stability and mRNA/ribosome interaction, and the location of the overlapping regions may be one of the keys to distinguishing the effects on mRNA stability from translatability. Although the precise mechanisms require further study, we believe that this hypothesis can, at least in part, unravel the mystery.

Another underlying mechanism of NAT-mediated mRNA stability and translatability is miRNA sponging. miRNAs often induce destabilization and translational repression of targeted mRNAs by binding to the 3' UTR [88]. By acting as ceRNAs to sponge miRNAs, NATs mask the binding sites between miRNAs and target mRNAs to inhibit miRNA-induced functions. For example, ZNFX1 antisense RNA 1 (ZFAS1) may upregulate the expression of BMI1, a major component of epigenetic repressor PRC1, by competitively binding $\mathrm{miR}-200 \mathrm{~b} / \mathrm{c}$, thereby driving tumorigenesis in osteosarcoma [89]. NATs can also regulate their cognate sense counterparts and contribute to malignant behaviors through this mechanism. The antisense IncRNA SOX9AS1 promotes the expression of its sense partner SOX9 at both RNA and protein levels by sponging miR-55903 p, thereby maintaining and facilitating the oncogenic functions of SOX9 in hepatocellular carcinoma [90].

Additionally, a special type of NATs, termed SINEUPs (SINE element-containing translation UP-regulators), has attracted attention due to their role in promoting the translation efficiency of the cognate sense mRNAs [91]. SINEUP activity was first demonstrated in mice: antisense lncRNA of Uchl1 promoted the translation efficiency of Uchl1 through antisense/sense binding, in which the overlapping region on the antisense transcript contains a SINEB2 domain to drive SINEUPs activity [92]. Similarly, in human cells, NAT of PPP1R12A exerts SINEUP activity to facilitate PPP1R12A translation [93].

Finally, dysregulated PTMs, which mainly consist of phosphorylation and ubiquitination, are profoundly implicated in tumorigenesis and chemoresistance by regulating protein activity and stability [94]. As expected, NATs, which can be found in almost every biological process, also modulate PTMs. ASB16-AS1, a NAT that promotes tumor growth in vivo and attenuates cisplatininduced cell apoptosis in gastric cancer, has been identified as a regulator of PTM. Specifically, TRIM37 phosphorylation exerts oncogenic functions in gastric cancer. ASB16-AS1 can recruit ATM, a protein kinase, to TRIM37 by forming physical bindings with ATM and TRIM37, inducing TRIM37 phosphorylation and synergistically facilitating malignant phenotypes [95]. An example of ubiquitination is HOTAIR. HOTAIR can bind to RUNX3 protein, which functions as a tumor suppressor in multiple malignancies, and promote the interaction between RUNX3 and the E3 ubiquitin ligase MEX3B, inducing degradation via MEX3B-mediated ubiquitination $[31,96]$.

\section{NATs in the hallmarks of cancer}

Carcinogenesis is a multistage process that results from dysregulated intracellular networks that unlocks a Pandora's box of disease and from intercellular communication that hides malignancy by orchestrating the tumor microenvironment (TME). In this manner, the integrated intracellular and intercellular cross-talk contributes to the hallmarks of cancer, as described by Hanahan and Weinberg in 2011 [22], and ultimately drives malignant phenotypes [97, 98]. NATs extensively participate in the hallmarks of cancer (Fig. 4) via the abovementioned molecular mechanisms, either separately or simultaneously. Here, we discuss the emerging roles of NATs in the hallmarks of cancer to demonstrate an up-to-date understanding of this rapidly developing field. While we did our best to cover this topic, some additional publications may also help get the full picture [99-102].

\section{Sustaining proliferative signaling}

Normal cells are regulated by growth signals and inhibitory factors to maintain homeostasis and the architecture and functions of tissues and organs. In contrast, cancer cells employ a variety of mechanisms to reduce their dependence on external growth signals, leading to 


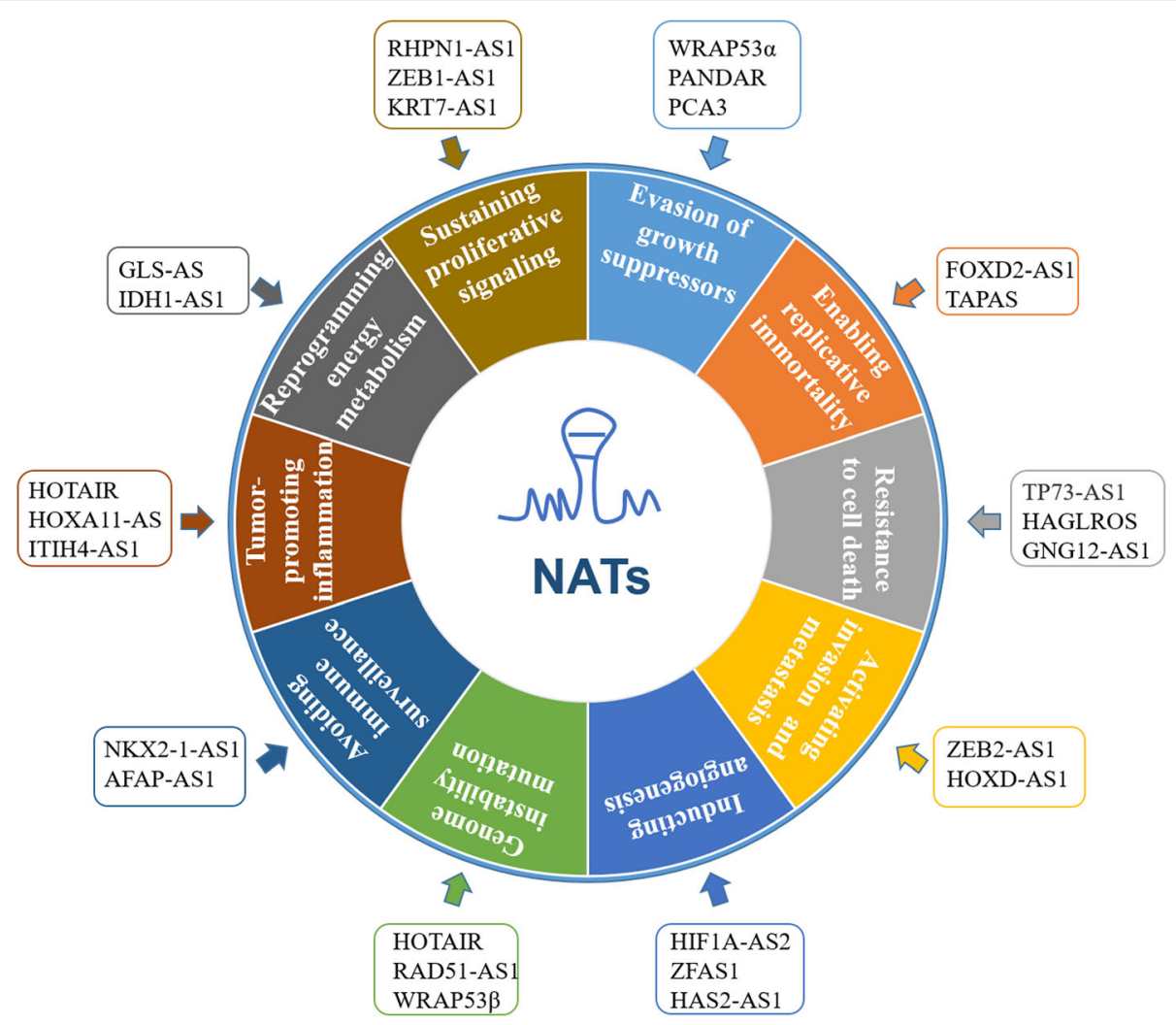

Fig. 4 NATs contribute to each of the hallmarks of cancer

sustained proliferation: (1) Producing growth factors and cognate receptors themselves to stimulate autocrine proliferation. (2) Stimulating tumor-associated stroma, which in turn produces growth factors, achieving sustained proliferation in a paracrine manner. (3) Promoting the expression of growth factor receptors, rendering cancer cells hyper-responsive to proliferative signals. (4) Altering or destroying proliferative signaling pathways, leading to cancer cells escaping the restraint of exogenous proliferative signals $[22,102]$. As ubiquitous regulators, NATs have demonstrated their important roles in sustaining cancer cell proliferation. RHPN1 antisense RNA1 (RHPN1-AS1) upregulates the expression of fibroblast growth factor 2 (FGF2), a potent regulator of mitogenic activity [103], by binding to miR-299-3p, thereby promoting cervical cancer cell proliferation [104]. Apart from regulating growth factor expression, NATs can also promote proliferation by modulating receptor abundance and the downstream signaling pathways. EGFR (epidermal growth factor receptor) and HER2, members of the EGFR family, play critical roles in sustaining cancer cell proliferation, aided by the downstream ERK1/2 signaling pathway. In hepatocellular carcinoma, the NAT MYLK-AS1 can increase EGFR and HER2 expression and subsequently trigger the
ERK1/2 signaling pathway, leading to increased cancer cell proliferation [105].

\section{Evasion of growth suppressors}

Tumor suppressor genes, known as the guardians of the genome, are in charge of the fate of the cell by regulating the cell cycle and apoptosis [106]. Therefore, cancer cells must escape these genes to survive and progress, in addition to the induction and maintenance of growthstimulating signals. TP53 and PTEN, two canonical tumor suppressors, are key nodes in the biological networks implicated in the evasion of growth suppressors [107, 108]. Accumulating evidence shows that NATsmediated TP53 and PTEN dysregulation participate in the evasion of cancer cells from tumor-suppressing functions. PANDAR (promoter of CDKN1A antisense DNA damage activated RNA) can interact with its binding protein SFRS2, a splicing factor that negatively regulates TP53 expression and phosphorylation, thereby facilitating the evasion of growth suppressor in ovarian cancer [109]. Other than PANDAR, the NAT WRAP53 $\alpha$ also regulates TP53. Specifically, WRAP53 $\alpha$ overlaps with the 5' UTR of TP53 mRNA to form an antisense/sense duplex, thereby protecting TP53 from degradation and consequently increasing TP53 mRNA and protein levels. 
Through this mechanism, silencing WRAP53 $\alpha$ attenuates TP53-induced apoptosis in breast cancer cells carrying wild-type TP53 [110]. PTEN can be epigenetically silenced by DNMT3a-mediated methylation under the guidance of its antisense counterpart [56].

\section{Enabling replicative immortality}

Apart from interfering with growth signals, cancer cells also harbor the characteristic of replicative immortality [102]. The telomere, located at the end of chromosome, is critical for the replication limits in normal cells. The telomere shortens gradually as the number of cell divisions increases. Hence, the telomere length indicates and further dictates the potential of cell replication. In contrast, cancer cells can circumvent the replication barrier posed by telomere shortening mainly by overexpressing telomerase, an enzyme that can maintain telomere length, and thereby gain the characteristic of replicative immortality $[111,112]$. Recent studies have indicated that specific NATs may be involved in regulating telomerase expression. As an imprinted oncogenic NAT, FOXD2AS1 can upregulate the expression of telomerase reverse transcriptase (TERT), the catalytic subunit of telomerase, by sponging miR-7-5p, maintaining and facilitating cancer stem cell phenotypes in thyroid cancer [113]. Another interesting finding is that TERT itself has an antisense partner, termed TERT antisense promoter-associated (TAPAS) RNA. In human embryonic stem cells, immortalized B-cells, and several primary tumor samples, TAPAS expression correlates negatively with TERT expression, implying a role for TAPAS in modulating replicative immortality [114].

\section{Resistance to cell death}

Unlimited replication does not ultimately lead to immortality. Therefore, another hallmark of cancer cells is the ability to successfully circumvent the cell death barrier, in addition to maintaining a continuous state of division. As controlled cell death processes, apoptosis and autophagy are considered essential for maintaining the homeostasis of cell death $[115,116]$. The PI3K/AKT/mTOR pathway has long been identified as a powerful intersection between the regulatory networks of apoptosis and autophagy [22, 117]. The $\mathrm{PI} 3 \mathrm{~K} / \mathrm{AKT} / \mathrm{mTOR}$ pathway is often deregulated in cancer [118]; notably, accumulating evidence demonstrates that specific NATs can regulate the pathway to shape the malignant phenotypes that facilitate the resistance to cell death. In drug-resistant breast cancer cells, HOTAIR can downregulate the resistance by attenuating the PI3K/AKT/mTOR pathway [119]. In clear cell renal cell carcinoma, TP73-AS1 inhibits the transcription of KISS1, a negative regulator of the $\mathrm{PI} 3 \mathrm{~K} / \mathrm{AKT} / \mathrm{mTOR}$ pathway, by recruiting EZH2, the catalytic subunit of PRC2, thereby reducing cell death [120]. In colorectal cancer cells, HAGLROS (HOXD antisense growth-associated lncRNA) regulates apoptosis and autophagy to resist cell death; the PI3K/ AKT/mTOR pathway and ATG5, a biomarker of autophagy, are the possible functional targets of HAGL ROS [121]. Apart from the PI3K/AKT/mTOR pathway, NATs can also mediate other molecules directly or indirectly associated with resistance to cell death. Compelling functional studies have validated this in numerous cancer types, such as the involvement of the NATs ZEB1-AS1 [42], PANDAR [109], and WRAP53 $\alpha$ [110].

\section{Activation of invasion and metastasis}

When cancers progress from residency in epithelial tissues to higher pathological grades of malignancy, they exhibit characteristics of local invasion and distant metastasis. Frequently, cancer cells enter the invasionmetastasis cascade first by invading the barrier of cellcell/cell-matrix adhesion, in which EMT is prominently implicated [122, 123]. As a pivotal biomarker of cell-cell adhesion, E-cadherin maintains the integrity of epithelial cell layers and often exerts a tumor-suppressive function. The loss of E-cadherin drives cancer cell invasion and metastasis by modulating EMT, while the upregulation of E-cadherin attenuates such phenotypes [124]. There are various means of regulating E-cadherin, which include ZEB2-AS1 and HOTAIR. Specifically, ZEB2-AS1 overlaps with the intron of the ZEB2 5' UTR, in which contains an IRES, enhancing the translation efficiency of ZEB2, a transcriptional suppressor of E-cadherin, and consequently leading to the downregulation of E-cadherin in breast cancer [68]. In oral squamous cell carcinoma, HOTAIR recruits EZH2 to induce H3K27me3 of the E-cadherin promoter and thus silences E-cadherin expression, consequently potentiating invasion and metastasis [125]. Moreover, HOTAIR is often overexpressed and may serve as a promising biomarker of distant metastasis in various cancer types $[24,125,126]$.

EMT is activated not only by the disruption of cell-cell adhesion, but also by the cell-matrix crosstalk, in which the matrix metalloproteinases (MMPs) play an important role in inducing breakdown of the extracellular matrix and subsequently paving the way for cancer cell invasion and metastasis [123, 127]. MMP9, an MMP family member [127], is overexpressed in multiple cancers and can be regulated by various NATs. In non-small cell lung cancer, HOXD-AS1 promotes MMP9 expression by sponging miR-133b, facilitating migration and invasion [128]. In ovarian cancer, TP73-AS1 potentiates metastasis by 
upregulating MMP9 [129]. These are simple examples, but they also provide solid evidence for NATs involvement in EMT. Future studies on identification of such NATs may broaden the scope of regulation of invasion and metastasis.

\section{Induction of angiogenesis}

Blood vessels play an important role in maintaining tissue and cell functions, allowing the import of nutrients and oxygen, and the export of metabolic waste and carbon dioxide [130]. In general, angiogenesis is restricted to embryogenesis. In adults, under certain conditions, such as female reproductive cycling and wound healing, the so-called angiogenesis switch can be switched on transiently. In contrast, angiogenesis is switched on and remains on in cancer, which leads to the constant growth of new vessels for sustaining tumor growth [22, 123]. Also, as the Chinese proverb states, "Before soldiers and horses move, provisions and grass go first," cancer cells therefore must control the angiogenesis switch to provide a precondition for tumorigenesis and progression [131]. As the most intensively studied proangiogenic pathway, the HIF1A/ VEGFA (hypoxia-inducible factor 1-alpha/vascular endothelial growth factor A) pathway is strengthened in various malignancies, and its strength correlates with multiple malignant phenotypes [132, 133]. NATs also regulate the angiogenesis hallmark by interacting with the HIF1A/VEGFA pathway. HIF1A-AS2, a NAT of HIF1A, also known as aHIF, was previously considered a negative regulator of HIF1A in a computer analysis model. In this case, the HIF1A 3' UTR may present as a hairpin structure, containing AU-rich elements (AREs) that may induce mRNA decay. HIF1AAS2 may also overlap with the HIF1A 3' UTR, thereby unfolding the hairpin structure to facilitate HIF1A mRNA degradation [134]. A few studies have discussed this hypothesis, such as in non-small cell lung cancer [135] and ovarian cancer [136], but it has not been validated experimentally. Despite that, HIF1A-AS2 can promote HIF1A expression and regulate the HIF1A/VEGFA pathway by sponging miR548c-3p, exerting a proangiogenic function in breast cancer [137]. In bladder cancer samples following treatment with cisplatin (a chemotherapy drug), HIF1A-AS2 and HIF1A are both overexpressed and correlate positively [138]. Therefore, HIF1A-AS2 might regulate HIF1A expression in a tissue-specific manner. Further studies are needed to reveal the underlying mechanisms. Additionally, other NATs can also regulate angiogenesis by interacting with the HIF1A/VEGFA pathway, either as an upstream regulator (e.g., ZFAS1 [139]) or as a downstream effector (e.g., HAS2-AS1 [140]).

\section{Genome instability and mutation}

Cancer is a genetic disease; genomic alteration is considered the trigger of the hallmarks described above [22]. Briefly, genomic alteration may confer selective advantages on cellular growth, and cell viability and motility, enabling tumorigenesis and progression. Genome instability and mutation are the main forms of genomic alteration. As discussed earlier, epigenetic modifications induce genome instability via DNA methylation and histone modifications, leading to epigenetic repression of target genes and consequently being implicated in malignant phenotypes. As NATs are predominantly located in the nucleus, it is not surprising to find that they play a role in epigenetic mechanisms. Still taking HOTAIR as an example, despite it being able to induce H3K27me3 to silence target genes, HOTAIR can also suppress $\mathrm{H} 3 \mathrm{~K} 27 \mathrm{ac}$ to achieve epigenetic repression. In gastric cancer, HOTAIR-mediated dynamic homeostasis between H3K27me3 and H3K27ac regulates the stability and transcription of the E-cadherin gene. Specifically, knockdown of HOTAIR attenuates H3K27me3 of the Ecadherin promoter and derepresses H3K27ac, thereby increasing E-cadherin expression and consequently inhibiting cancer cell EMT [125]. In addition, telomere shortening also facilitates genome instability. In this case, additional telomere shortening may induce telomere crisis, which compromises the protective effect of the telomere on the chromosome end, ultimately causing extensive genome instability to drive tumorigenesis. Telomerase, which restores telomere length, is therefore critical for avoiding telomere crisis and maintaining genome integrity [141-143]. However, as described above, telomerase overexpression enables replicative immortality, indicating the double-edged effects of telomerase on the hallmarks of cancer. Therefore, NATs such as FOXD2-AS1 and TAPAS, which regulate telomerase expression, may also regulate genome stability. Further studies on identifying NATs that regulate telomerase and on balancing the advantages and disadvantages of telomerase may shed light on NAT-mediated genome alteration.

Furthermore, genome instability contributes to mutations of the hallmark-enabling genes under the condition of genome maintenance machinery dysfunction. RAD51 is a hub protein involved in the DNA repair machinery through homologous recombination. Malfunction of RAD51 is considered as a critical event driving genome instability and tumorigenesis [144]. In hepatocellular carcinoma cells, RAD51 has a negative correlation with its antisense partner, RAD51-AS1. Silencing RAD51-AS1 increases RAD51 protein expression significantly without altering RAD51 mRNA levels [145]. Moreover, this is not the only example of NAT-mediated genome mutations. In glioblastoma, HMMR-AS1 interferes with the 
translation of RAD51 and ATM (a master controller of DNA repair) [146]. WRAP53 $\beta$ (also known as WDR79), another TP53 NAT independent of WRAP53 $\alpha$, mediates DNA repair with the participation of RAD51 and ATM in various cancer cell lines [147]; in addition, the expression of WRAP53 $\beta$ protein correlates positively with TP53 mutations in non-small cell lung cancer samples [148]. Although the underlying mechanisms are not known, these findings provide concrete evidence that NATs can be involved in the machinery of genome mutations.

Notably, NATs themselves may give rise to functional mutations. The lncRNA SIRT1-AS can increase the stability of its sense counterpart, SIRT1 mRNA (a histone deacetylase that deeply participates in genome stability maintenance [149], and EMT [150]), by sponging miR29c, facilitating hepatocellular carcinoma cell proliferation. However, a single-nucleotide mutation has been observed in SIRT1-AS; it decreases the risk of hepatocellular carcinoma possibly by altering the secondary structure of SIRT1-AS and preventing binding to SIRT1 mRNA [151]. Taken together, these NATs depict a preliminary outline of their promising potential in regulating genome instability and mutation.

\section{Avoidance of immune detection and destruction}

Under constant surveillance of the immune system, human body maintains a dynamic homeostasis to provide protection against tumor. Therefore, disrupting the equilibrium and avoiding identification and/or elimination by the immune surveillance is a primary task in tumor survival $[22,152]$. Notably, genome instability and mutations result in tumor heterogeneity, endowing different cancer cell subclones with varying sensitivity to immune surveillance [152]. The immune system can detect, target, and destroy sensitive cancer cells, while nonsensitive cancer cells are invisible to immune surveillance, thereby achieving the tasks of surviving and thriving. From this perspective, the immune system is a double-edged sword, not only exerting an antitumor effect, but also inadvertently selecting tumor variants that are undetectable and indestructible by the immune system, consequently promoting tumor evolution. Further, the immune checkpoints render cancer cells invisible. Programmed cell death 1 (PD1) and PD1 ligand 1 (PD-L1), the well-defined immune checkpoints that exert stimulatory or inhibitory functions on the immune response, are considered the key to the disequilibrium [153]. NAT-mediated dysregulation of PD1/PD-L1 induces immune tolerance, enabling cancer cells to escape from immune detection and destruction. In lung cancer cells, NKX2-1-AS1, the NAT of the transcription factor NKX2-1, is a negative regulator of PD-L1 mRNA and protein levels. Further examinations have validated the fact that NKX2-1-AS1 acts as a decoy to prevent NKX2-1 from binding the PD-L1 promoter, thereby decreasing PD-L1 transcription, and ultimately leading to attenuated evasion of the immune system [154]. Another NAT, AFAP-AS1, correlates positively with PD1 in nasopharyngeal carcinoma [155]. These examples indicate that NATs may play a role in regulating immune checkpoints. Further efforts on: (1) identifying of NATs that participate in the immune surveillance networks; (2) exploring the functions and underlying mechanisms of immune-NATs; (3) applying immune-NAT targeted molecules in cancer therapy, either alone or in combination with immunotherapy, will greatly deepen our understanding of the sophisticated interaction between NATs and immune surveillance. In addition, escape from immune surveillance does not occur independently; it is closely intertwined with tumor-associated inflammation, which is discussed in the next section.

\section{Tumor-promoting inflammation}

Inflammation goes through every stage of tumorigenesis and progression [156]. Together with cancer cells, stromal cells, and immune cells, inflammatory cells can shape malignant characteristics and phenotypes by orchestrating an inflammatory TME [156, 157]. Functionally, inflammation acts as a double-edged sword in cancer, much like the immune system. Simply put, inflammation can induce, and vice versa, genome instability and oncogenic mutations and compromise the immune surveillance system, creating a tumorpromoting TME to enrich malignant transformation and accelerate tumor progression by directly releasing oncogenic signals and/or interacting with other TME components. On the other hand, inflammation can reinforce immune surveillance by enhancing immune cell infiltration into tumors, thereby switching TME to a tumor-suppressing direction [158-160]. The dynamic crosstalk between the tumor-promoting and tumorsuppressing signals is, to some extent, a master controller of tumorigenesis. It is well established that nuclear factor- $\mathrm{kB} /$ signal transducer and activator of transcription 3 (NF-kB/STAT3), the well-defined regulatory hubs of tumor-associated inflammation, play pivotal roles in maintaining the delicate crosstalk. Dysregulation of NF$\kappa \mathrm{B} / \mathrm{STAT} 3$ will upset the delicate balance, leading to a predisposition to the pro-tumorigenic direction and ultimately driving tumor initiation and progression [161163]. Therefore, it is important to fully uncover the sophisticated networks of NF-kB /STAT3 and to determine how they can be fine-tuned to exert antitumorigenic functions. NATs, which have demonstrated their roles in tumor-associated inflammation, may provide insights into the networks. HOTAIR is overexpressed in ovarian cancer, which induces NF-kB 
activation and the subsequent secretion of IL-6 (an NF$\kappa B$ downstream molecule that activates STAT3, also playing a critical role in reprogramming the TME [164]) by suppressing Ік-B $\alpha$ (an NF- $k B$ inhibitor). Furthermore, $\mathrm{NF}-\mathrm{kB}$ exerts its functions as a transcription factor to bind the promoter of HOTAIR, thus forming an NF-kBHOTAIR positive feedback loop and driving malignant phenotypes [165]. Additional studies have shown that HOTAIR can directly or indirectly regulate STAT3 in a reciprocal manner in multiple malignancies $[30,166$, 167]. HOTAIR is not the only example of NATmediated tumor-associated inflammation. Briefly, HOXA11-AS regulates STAT3 expression by acting as a miRNA sponge in liver cancer, thereby accelerating tumor growth and metastasis [168]. In colorectal cancer, ITIH4-AS1 facilitates tumorigenesis and progression by modulating STAT3 phosphorylation [169]. These investigations present credible clues for NAT regulation of NF-kB/STAT3, and shed light on tumor-associated inflammation.

\section{Reprogramming energy metabolism}

Metabolism fuels life, whether in cancer cells or in normal cells. However, metabolism in cancer cells has distinct characteristics when compared with that in normal cells. Although the underlying mechanisms of this phenomenon remain to be unveiled, the Warburg effect may provide inspiring insights. The Warburg effect refers to the phenomenon where, regardless of sufficient oxygen, cancer cells reprogram their metabolism phenotypes to acquire a preference for glycolysis $[170,171]$. Through glycolysis, cancer cells produce the glycolytic intermediates necessary for rapid proliferation [172] and create an acidic microenvironment favorable for EMT [173]. Accordingly, the Warburg effect caused by the reprogrammed metabolism can shield the onset and progression of cancer. From this perspective, cancer can also be considered a metabolic disease. Mechanistically, cancer cells flip the metabolic switch largely by modulating central metabolic molecules, such as c-MYC [174] and HIF1A [175]. Notably, c-MYC cooperates with HIF1A to promote glycolysis in response to hypoxia [174]. As discussed earlier, c-MYC can be regulated by GLS-AS in an RNAi-dependent manner, and the correlation of HIF1A to multiple NATs has been demonstrated. Therefore, it would be intriguing to explore whether NATs are involved in the cooperation between c-MYC and HIF1A. IDH1-AS1 is a NAT transcribed from the opposite direction of IDH1, which encodes a key enzyme in metabolism and induces HIF1A degradation by forming a homodimer structure. IDH1-AS1 can physically bind IDH1 to promote its homodimerization, leading to increased IDH1 enzymatic activity and consequently accelerating HIF1A degradation. c-MYC can decrease IDH1 activity through transcriptional inhibition of IDH1-AS1. In this manner, IDH1-AS1 acts as a bridge between c-MYC and HIF1A and attenuates the activation of the Warburg effect [176].

Notably, as the enabling characteristics, destabilized genome, disequilibrated immune surveillance, tumorassociated inflammation, and reprogrammed metabolism are complementary and intricately intertwined $[22,123]$. They coordinate with each other to create the cancer seed and fertilize the soil. Protein is the executor of biological function [177], while NATs mainly consist of ncRNAs [12]. In addition, NATs have not attracted much attention. Altogether, this renders NATs obscure. Despite these concerns, NATs have proven to be powerful, yet sidelined, regulators, fine-tuning every hallmark of cancer.

\section{Therapeutic promise in targeting NATs}

NATs are ubiquitous in all branches of life and deeply participate in the diverse hallmarks of cancer. The expression of NATs generally demonstrates a highly celland/or tissue-specific pattern [178], making NATs promising candidates for therapeutic targets. Multiple approaches have been explored for targeting NATs: (1) RNAi by using siRNAs, shRNAs, and miRNAs. RNAi reduces RNA stability or mRNA translatability in an AGO2-dependent cleavage manner [77]. Contrary to AGO2, which is predominantly expressed in the cytoplasm, NATs are preferentially located in the nucleus [179]. Therefore, the effect of RNAi-mediated knockdown on NATs may be compromised. (2) Antisense oligonucleotides (ASOs). Typically, ASOs are synthetic antisense oligonucleotides that may form a DNA-RNA hybrid with target RNA and thereby induce RNase $\mathrm{H}$ mediated RNA degradation. As RNase $\mathrm{H}$ is predominantly expressed in the nucleus, ASOs have a significant advantage over RNAi in targeting nuclear NATs. Particularly, the ASOs designed for inhibiting cis-NATs are termed antagoNATs [178], which may block the interaction between antisense and sense transcripts and subsequently result in NAT degradation and transcriptional derepression of the overlapping/neighboring sense counterparts. Although RNAi- and ASO-based therapies have attracted keen interest in loss-of-function studies on NATs, practical obstacles remain to be solved before clinical application can be achieved, such as off-target effects, insufficient cellular uptake, and cytotoxicity [ 77 , 180]. Hopefully, the development of gene-editing technologies has emerged as an alternative approach for NAT-targeted therapy. (3) Clustered regularly interspaced short palindromic repeats (CRISPR)/Cas9. Cancer is a genetic disease. Correcting pathogenic gene aberrations using gene-editing technologies may be a promising therapeutic strategy in the battle against 
cancer. As a versatile gene-editing tool, CRISPR/Cas9 makes it possible, under the guidance of single guide RNA (sgRNA), to achieve knock-out/knock-in or transcriptional inhibition/activation of NATs involved in the hallmarks of cancer [181, 182]. Compared with RNAi and ASOs, CRISPR has reduced off-target effects, better efficacy, and consistent activity. However, many NATs overlap with or are adjacent to other genes, and this may hinder the specificity of CRISPR/Cas9-mediated genetic manipulation. A genome-wide study found that only $15 \%$ of antisense lncRNAs could be edited safely by CRISPR [183]. We speculate that high-specificity sgRNA is a precondition for CRISPR, and NATs without any intersection with other genes might be more amenable to CRISPR. (4) Other approaches, such as viruses, nanomedicine, morpholinos, and small molecules [180, 184], may also shed light on NATs-targeted therapy through various mechanisms.

Taken together, these approaches have their intrinsic advantages and disadvantages and may complement each other. A reasonable strategy might be choosing the appropriate approach or combination approaches according to the cellular localization of the target NAT.

\section{Conclusions}

NATs are dysregulated in various cancers and are implicated in multiple malignant phenotypes. Therefore, comprehensive understanding of their features and mechanisms of functions is critical for appreciating the importance of this particular class of molecules. Recent studies demonstrate that NATs are emerging as important players in the hallmarks of cancer via their involvement in diverse stages of gene expression regulation, from controlling epigenetic modifications to modulating mRNA PTMs. Indeed, several preclinical experiments have demonstrated promising results after targeting NATs using RNAi-, ASO-, or CRISPR-based approaches $[168,178,185]$. We are just beginning to unravel the mystery of their generation, functions, and mechanisms, and exploring their potential as diagnostic biomarkers and therapeutic targets.

Despite these exciting advancements, the limitations and challenges should not be ignored. First, NATs generally demonstrate relatively low abundance compared with their sense counterparts [186], rendering their annotation challenging. However, the relative low expression and preferential nuclear localization of NATs implies that NATs mainly act in cis as transcriptional regulators, and that small changes may make a big difference. Further investigation is needed to evaluate these possibilities comprehensively. Second, most NATs exhibit limited conservation across species. The investigation of NATs may therefore be obstructed by preclinical evaluation in animal models. Lastly, the overlap between NATs and their sense counterparts may hamper the specificity and safety of NAT-targeted therapy via off-target effects and cytotoxicity. A detailed bioinformatics analysis for eliminating non-specific binding and designing multiple sequences to target different regions of NAT may minimize these adverse effects. However, such approaches are not always practical.

In conclusion, significant evidence of NATs in the cancer hallmarks is being uncovered constantly despite the above limitations and challenges. We have just begun to scratch the surface of NATs. We believe that our knowledge of gene regulation by NATs will continue to expand. Further studies for clarifying their underlying mechanisms of function and for exploring appropriate therapeutic targets will lead to a novel and promising avenue for cancer therapy.

\section{Abbreviations}

NATs: Natural antisense transcripts; ncRNA: Non-coding RNA; IncRNA: Long non-coding RNA; TSS: Transcriptional start site; H3K27me3: Histone H3 lysine 27 trimethylation; H3K27ac: Histone H3 lysine 27 acetylation; HATs: Histone acetyltransferases; ceRNA: Competing endogenous RNA; DNMT3a: DNA methyltransferase 3a; RNAP: RNA polymerase; EMT: Endothelial-mesenchymal transition; UTR: Untranslated region; IRES: Internal ribosome entry site; dsRNA: Double stranded RNA; A-to-I: Adenosine-to-inosine (A-to-l);

PTMs: Post-translational modifications; RNAi: RNA interference; SINEUPs: SINE element-containing translation UP-regulators; TME: Tumor microenvironment; EGFR: Epidermal growth factor receptor; HAGLROS: HOXD antisense growthassociated IncRNA; HIF1A: Hypoxia-inducible factor 1-alpha; VEGFA: Vascular endothelial growth factor A; TERT: Telomerase reverse transcriptase; TAPA S: TERT antisense promoter-associated; MMPs: Matrix metalloproteinases; AREs: AU-rich elements; PD1: Programmed cell death 1; PD-L1: Programmed cell death 1 ligand 1; ASO: Antisense oligonucleotides; CRISPR: Clustered regularly interspaced short palindromic repeats; sgRNA: Single guide RNA

\section{Acknowledgements}

Not applicable.

\section{Authors' contributions}

SZ and SZ wrote the review article. XZ and SC reviewed the manuscript. All authors read and approved the final manuscript.

\section{Funding}

This study was supported by the China Postdoctoral Science Foundation (No. 2020M670095ZX)

Availability of data and materials

Data sharing not applicable to this article as no datasets were generated or analyzed during the current study.

Conflict of Interest

There are no known conflicts of interest.

Ethics approval and consent to participate

Not applicable.

Consent for publication

Not applicable.

Competing interests

The authors declare that they have no competing interests.

Author details

${ }^{1}$ Key Laboratory of Reproductive Dysfunction Diseases and Fertility Remodeling of Liaoning Province, Reproductive Medicine Center, Obstetrics and Gynecology Department, Shengjing Hospital Affiliated to China Medical 
University, 110022 Shenyang, Liaoning, China. ${ }^{2}$ Department of Epigenetics, China Medical University, 110122 Shenyang, Liaoning, China. ${ }^{3}$ Department of Gynecologic Oncology Research Office, The Third Affiliated Hospital of Guangzhou Medical University, 510150 Guangzhou, Guangdong, China. ${ }^{4}$ Department of Thoracic Surgery, The First Affiliated Hospital of China Medical University, 110001 Shenyang, Liaoning, China. ${ }^{5}$ Department of Environmental and Occupational Health, School of Public Health, China Medical University, 110122 Shenyang, Liaoning, China.

\section{Received: 9 April 2020 Accepted: 4 September 2020}

\section{Published online: 14 September 2020}

\section{References}

1. Mattick JS, Makunin IV. Non-coding RNA. Hum Mol Genet. 2006;15 Spec No 1:R17-29.

2. Schmitt AM, Chang HY. Long Noncoding RNAs in Cancer Pathways. Cancer Cell. 2016;29(4):452-63.

3. Rinn JL, Chang HY. Genome regulation by long noncoding RNAs. Annu Rev Biochem. 2012;81:145-66.

4. Lin C, Yang L. Long Noncoding RNA in Cancer: Wiring Signaling Circuitry. Trends Cell Biol. 2018;28(4):287-301.

5. Sun $H$, Huang Z, Sheng W, Xu MD. Emerging roles of long non-coding RNAs in tumor metabolism. J Hematol Oncol. 2018;11(1):106.

6. Leucci E. Cancer development and therapy resistance: spotlights on the dark side of the genome. Pharmacol Ther. 2018;189:22-30.

7. Fan C, Tang Y, Wang J, Xiong F, Guo C, Wang Y, et al. Role of long noncoding RNAs in glucose metabolism in cancer. Mol Cancer. 2017;16(1):130.

8. Slack FJ, Chinnaiyan AM. The Role of Non-coding RNAs in Oncology. Cell. 2019;179(5):1033-55

9. Chan JJ, Tay Y. Noncoding RNA:RNA Regulatory Networks in Cancer. Int J Mol Sci. 2018;19(5):1310.

10. Li JT, Zhang Y, Kong L, Liu QR, Wei L. Trans-natural antisense transcripts including noncoding RNAs in 10 species: implications for expression regulation. Nucleic Acids Res. 2008;36(15):4833-44.

11. Pelechano $V$, Steinmetz LM. Gene regulation by antisense transcription. Nat Rev Genet. 2013;14(12):880-93.

12. Faghihi MA, Wahlestedt $C$. Regulatory roles of natural antisense transcripts. Nat Rev Mol Cell Biol. 2009;10(9):637-43.

13. Katayama S, Tomaru Y, Kasukawa T, Waki K, Nakanishi M, Nakamura M, et al. Antisense transcription in the mammalian transcriptome. Science. 2005; 309(5740):1564-6.

14. Wang J, Li Z, Liu B, Chen G, Shao N, Ying X, et al. Systematic study of cisantisense miRNAs in animal species reveals miR-3661 to target PPP2CA in human cells. Rna. 2016;22(1):87-95.

15. Su WY, Li JT, Cui Y, Hong J, Du W, Wang YC, et al. Bidirectional regulation between WDR83 and its natural antisense transcript DHPS in gastric cancer. Cell Res. 2012;22(9):1374-89.

16. Lin JM, Collins PJ, Trinklein ND, Fu Y, Xi H, Myers RM, et al. Transcription factor binding and modified histones in human bidirectional promoters. Genome Res. 2007;17(6):818-27.

17. Balbin OA, Malik R, Dhanasekaran SM, Prensner JR, Cao X, Wu YM, et al. The landscape of antisense gene expression in human cancers. Genome Res. 2015;25(7):1068-79.

18. Quinn JJ, Chang HY. Unique features of long non-coding RNA biogenesis and function. Nat Rev Genet. 2016;17(1):47-62.

19. Vanhee-Brossollet $C$, Vaquero $C$. Do natural antisense transcripts make sense in eukaryotes? Gene. 1998;211(1):1-9.

20. Batista PJ, Chang HY. Long noncoding RNAs: cellular address codes in development and disease. Cell. 2013;152(6):1298-307.

21. Cui I, Cui H. Antisense RNAs and epigenetic regulation. Epigenomics. 2010; 2(1):139-50.

22. Hanahan D, Weinberg RA. Hallmarks of cancer: the next generation. Cell. 2011;144(5):646-74.

23. Flavahan WA, Gaskell E, Bernstein BE. Epigenetic plasticity and the hallmarks of cancer. Science. 2017:357(6348):eaal2380.

24. Gupta RA, Shah N, Wang KC, Kim J, Horlings HM, Wong DJ, et al. Long noncoding RNA HOTAIR reprograms chromatin state to promote cancer metastasis. Nature. 2010;464(7291):1071-6.

25. Bhan A, Mandal SS. LncRNA HOTAIR: A master regulator of chromatin dynamics and cancer. Biochim Biophys Acta. 2015;1856(1):151-64.
26. Milevskiy MJ, Al-Ejeh F, Saunus JM, Northwood KS, Bailey PJ, Betts JA, et al. Long-range regulators of the IncRNA HOTAIR enhance its prognostic potential in breast cancer. Hum Mol Genet. 2016;25(15):3269-83.

27. Xue $X$, Yang YA, Zhang A, Fong KW, Kim J, Song B, et al. LncRNA HOTAIR enhances ER signaling and confers tamoxifen resistance in breast cancer. Oncogene. 2016:35(21):2746-55.

28. Lu MY, Liao YW, Chen PY, Hsieh PL, Fang CY, Wu CY, et al. Targeting LncRNA HOTAIR suppresses cancer stemness and metastasis in oral carcinomas stem cells through modulation of EMT. Oncotarget. 2017;8(58):98542-52.

29. Pan $Y$, Wu Y, Hu J, Shan Y, Ma J, Ma H, et al. Long noncoding RNA HOTAIR promotes renal cell carcinoma malignancy through alpha-2, 8sialyltransferase 4 by sponging microRNA-124. Cell Prolif. 2018;51(6):e12507.

30. Sun S, Wu Y, Guo W, Yu F, Kong L, Ren Y, et al. STAT3/HOTAIR Signaling Axis Regulates HNSCC Growth in an EZH2-dependent Manner. Clin Cancer Res. 2018;24(11):2665-77.

31. Xue M, Chen LY, Wang WJ, Su TT, Shi LH, Wang $L$, et al. HOTAIR induces the ubiquitination of Runx3 by interacting with Mex3b and enhances the invasion of gastric cancer cells. Gastric Cancer. 2018;21(5):756-64.

32. Pastori C, Kapranov P, Penas C, Peschansky V, Volmar CH, Sarkaria JN, et al, The Bromodomain protein BRD4 controls HOTAIR, a long noncoding RNA essential for glioblastoma proliferation. Proc Natl Acad Sci U S A. 2015; 112(27):8326-31

33. Rupaimoole R, Slack FJ. MicroRNA therapeutics: towards a new era for the management of cancer and other diseases. Nat Rev Drug Discov. 2017;16(3): 203-22.

34. Xue JY, Huang C, Wang W, Li HB, Sun M, Xie M. HOXA11-AS: a novel regulator in human cancer proliferation and metastasis. Onco Targets Ther. 2018;11:4387-93.

35. Luo N, Zhang K, Li X, Hu Y. ZEB1 induced-upregulation of long noncoding RNA ZEB1-AS1 facilitates the progression of triple negative breast cancer by binding with ELAVL1 to maintain the stability of ZEB1 mRNA. J Cell Biochem. 2020;121(10):4176-87.

36. Meng L, Ma P, Cai R, Guan Q, Wang M, Jin B. Long noncoding RNA ZEB1AS1 promotes the tumorigenesis of glioma cancer cells by modulating the miR-200c/141-ZEB1 axis. Am J Transl Res. 2018;10(11):3395-412.

37. Zhao $Y$, Wang $N$, Zhang $X$, Liu H, Yang S. LnCRNA ZEB1-AS1 downregulation suppresses the proliferation and invasion by inhibiting ZEB1 expression in oesophageal squamous cell carcinoma. J Cell Mol Med. 2019; 23(12):8206-18

38. Qu R, Chen X, Zhang C. LncRNA ZEB1-AS1/miR-409-3p/ZEB1 feedback loop is involved in the progression of non-small cell lung cancer. Biochem Biophys Res Commun. 2018;507(1-4):450-6.

39. Cheng R, Li N, Yang S, Liu L, Han S. Long non-coding RNA ZEB1-AS1 promotes cell invasion and epithelial to mesenchymal transition through inducing ZEB1 expression in cervical cancer. Onco Targets Ther. 2018;11:7245-53.

40. Xiong WC, Han N, Wu N, Zhao KL, Han C, Wang HX, et al. Interplay between long noncoding RNA ZEB1-AS1 and miR-101/ZEB1 axis regulates proliferation and migration of colorectal cancer cells. Am J Transl Res. 2018; 10(2):605-17.

41. Su W, Xu M, Chen X, Chen N, Gong J, Nie L, et al. Long noncoding RNA ZEB1-AS1 epigenetically regulates the expressions of ZEB1 and downstream molecules in prostate cancer. Mol Cancer. 2017;16(1):142.

42. Zhao $X$, Wang D, Ding $Y$, Zhou J, Liu G, Ji Z. IncRNA ZEB1-AS1 promotes migration and metastasis of bladder cancer cells by post-transcriptional activation of ZEB1. Int J Mol Med. 2019;44(1):196-206.

43. Liu C, Lin J. Long noncoding RNA ZEB1-AS1 acts as an oncogene in osteosarcoma by epigenetically activating ZEB1. Am J Transl Res. 2016;8(10): 4095-105.

44. Liu H, Shin SH, Chen H, Liu T, Li Z, Hu Y, et al. CDK12 and PAK2 as novel therapeutic targets for human gastric cancer. Theranostics. 2020;10(14): 6201-15.

45. Coniglio SJ, Zavarella S, Symons MH. Pak1 and Pak2 mediate tumor cell invasion through distinct signaling mechanisms. Mol Cell Biol. 2008;28(12): 4162-72.

46. Ni X, Ding Y, Yuan H, Shao J, Yan Y, Guo R, et al. Long non-coding RNA ZEB1-AS1 promotes colon adenocarcinoma malignant progression via miR455-3p/PAK2 axis. Cell Prolif. 2020;53(1):e12723.

47. Khalil AM, Guttman M, Huarte M, Garber M, Raj A, Rivea Morales D, et al. Many human large intergenic noncoding RNAs associate with chromatinmodifying complexes and affect gene expression. Proc Natl Acad Sci U S A. 2009;106(28):11667-72 
48. Rajagopal T, Talluri S, Akshaya RL, Dunna NR. HOTAIR LncRNA: A novel oncogenic propellant in human cancer. Clin Chim Acta. 2020;503:1-18.

49. Tsai MC, Manor O, Wan Y, Mosammaparast N, Wang JK, Lan F, et al. Long noncoding RNA as modular scaffold of histone modification complexes. Science. 2010;329(5992):689-93.

50. Marchese FP, Huarte M. Long non-coding RNAs and chromatin modifiers: their place in the epigenetic code. Epigenetics. 2014;9(1):21-6.

51. Blank-Giwojna A, Postepska-Igielska A, Grummt I. IncRNA KHPS1 Activates a Poised Enhancer by Triplex-Dependent Recruitment of Epigenomic Regulators. Cell Rep. 2019;26(11):2904-15 e4.

52. Day FL, Jorissen RN, Lipton L, Mouradov D, Sakthianandeswaren A, Christie $M$, et al. PIK3CA and PTEN gene and exon mutation-specific clinicopathologic and molecular associations in colorectal cancer. Clin Cancer Res. 2013;19(12):3285-96.

53. Wang X, Cao X, Sun R, Tang C, Tzankov A, Zhang J, et al. Clinical Significance of PTEN Deletion, Mutation, and Loss of PTEN Expression in De Novo Diffuse Large B-Cell Lymphoma. Neoplasia. 2018;20(6):574-93.

54. Yang JM, Schiapparelli P, Nguyen HN, Igarashi A, Zhang Q, Abbadi S, et al. Characterization of PTEN mutations in brain cancer reveals that pten monoubiquitination promotes protein stability and nuclear localization. Oncogene. 2017;36(26):3673-85.

55. Jamaspishvili T, Berman DM, Ross AE, Scher HI, De Marzo AM, Squire JA, et al. Clinical implications of PTEN loss in prostate cancer. Nat Rev Urol. 2018;15(4):222-34

56. Lister N, Shevchenko G, Walshe JL, Groen J, Johnsson P, Vidarsdottir L, et al. The molecular dynamics of long noncoding RNA control of transcription in PTEN and its pseudogene. Proc Natl Acad Sci U S A. 2017;114(37):9942-7.

57. Bordoy AE, Varanasi US, Courtney CM, Chatterjee A. Transcriptional Interference in Convergent Promoters as a Means for Tunable Gene Expression. ACS Synth Biol. 2016;5(12):1331-41.

58. Shearwin KE, Callen BP, Egan JB. Transcriptional interference-a crash course. Trends Genet. 2005;21(6):339-45.

59. Latos PA, Pauler FM, Koerner MV, Senergin HB, Hudson QJ, Stocsits RR, et al. Airn transcriptional overlap, but not its IncRNA products, induces imprinted Igf2r silencing. Science. 2012;338(6113):1469-72.

60. Martin-Kleiner I, Gall Troselj K. Mannose-6-phosphate/insulin-like growth factor 2 receptor (M6P/IGF2R) in carcinogenesis. Cancer Lett. 2010; 289(1):11-22.

61. Hawkins PG, Santoso S, Adams C, Anest V, Morris KV. Promoter targeted small RNAs induce long-term transcriptional gene silencing in human cells. Nucleic Acids Res. 2009;37(9):2984-95.

62. Gagnon KT, Li L, Chu Y, Janowski BA, Corey DR. RNAi factors are present and active in human cell nuclei. Cell Rep. 2014;6(1):211-21.

63. Stojic L, Niemczyk M, Orjalo A, Ito $Y$, Ruijter AE, Uribe-Lewis $S$, et al. Transcriptional silencing of long noncoding RNA GNG12-AS1 uncouples its transcriptional and product-related functions. Nat Commun. 2016;7:10406.

64. Baralle FE, Giudice J. Alternative splicing as a regulator of development and tissue identity. Nat Rev Mol Cell Biol. 2017;18(7):437-51

65. Romero-Barrios N, Legascue MF, Benhamed M, Ariel F, Crespi M. Splicing regulation by long noncoding RNAs. Nucleic Acids Res. 2018;46(5):2169-84.

66. Zhu L, Chen L. Progress in research on paclitaxel and tumor immunotherapy. Cell Mol Biol Lett. 2019;24:40.

67. Xu S, Wang P, Zhang J, Wu H, Sui S, Zhang J, et al. Ai-IncRNA EGOT enhancing autophagy sensitizes paclitaxel cytotoxicity via upregulation of ITPR1 expression by RNA-RNA and RNA-protein interactions in human cancer. Mol Cancer. 2019;18(1):89.

68. Beltran M, Puig I, Pena C, Garcia JM, Alvarez AB, Pena R, et al. A natural antisense transcript regulates Zeb2/Sip1 gene expression during Snail1induced epithelial-mesenchymal transition. Genes Dev. 2008;22(6):756-69.

69. Fardi M, Alivand M, Baradaran B, Farshdousti Hagh M, Solali S. The crucial role of ZEB2: From development to epithelial-to-mesenchymal transition and cancer complexity. J Cell Physiol. Online ahead of print at https://doi. org/10.1002/jcp.28277(2019).

70. Gonzalez I, Munita R, Agirre E, Dittmer TA, Gysling K, Misteli T, et al. A IncRNA regulates alternative splicing via establishment of a splicing-specific chromatin signature. Nat Struct Mol Biol. 2015;22(5):370-6.

71. Salameh A, Lee AK, Cardo-Vila M, Nunes DN, Efstathiou E, Staquicini Fl, et al. PRUNE2 is a human prostate cancer suppressor regulated by the intronic long noncoding RNA PCA3. Proc Natl Acad Sci U S A. 2015;112(27):8403-8.

72. Nishikura K. Functions and regulation of RNA editing by ADAR deaminases. Annu Rev Biochem. 2010;79:321-49.
73. Han L, Diao L, Yu S, Xu X, Li J, Zhang R, et al. The Genomic Landscape and Clinical Relevance of A-to-I RNA Editing in Human Cancers. Cancer Cell. 2015;28(4):515-28

74. Ma CP, Liu H, Yi-Feng Chang I, Wang WC, Chen YT, Wu SM, et al. ADAR1 promotes robust hypoxia signaling via distinct regulation of multiple HIF1alpha-inhibiting factors. EMBO reports. 2019;20(5):e47107.

75. Rashid F, Shah A, Shan G. Long Non-coding RNAs in the Cytoplasm. Genom Proteom Bioinform. 2016;14(2):73-80.

76. Nishizawa M, Okumura T, Ikeya Y, Kimura T. Regulation of inducible gene expression by natural antisense transcripts. Frontiers in bioscience. 2012;17: 938-58.

77. Setten RL, Rossi JJ, Han SP. The current state and future directions of RNAibased therapeutics. Nat Rev Drug Discov. 2019;18(6):421-46.

78. Ota H, Sakurai M, Gupta R, Valente L, Wulff BE, Ariyoshi K, et al. ADAR1 forms a complex with Dicer to promote microRNA processing and RNAinduced gene silencing. Cell. 2013;153(3):575-89.

79. Masisi BK, El Ansari R, Alfarsi L, Rakha EA, Green AR, Craze ML. The role of glutaminase in cancer. Histopathology. 2020;76(4):498-508.

80. Deng SJ, Chen HY, Zeng Z, Deng S, Zhu S, Ye Z, et al. Nutrient StressDysregulated Antisense IncRNA GLS-AS Impairs GLS-Mediated Metabolism and Represses Pancreatic Cancer Progression. Cancer Res. 2019;79(7):1398-412.

81. Lebedeva S, Jens M, Theil K, Schwanhausser B, Selbach M, Landthaler M et al. Transcriptome-wide analysis of regulatory interactions of the RNAbinding protein HuR. Mol Cell. 2011:43(3):340-52.

82. Jadaliha M, Gholamalamdari O, Tang W, Zhang Y, Petracovici A, Hao Q, et al. A natural antisense IncRNA controls breast cancer progression by promoting tumor suppressor gene mRNA stability. PLoS Genet. 2018;14(11): e1007802.

83. Huang B, Song JH, Cheng Y, Abraham JM, Ibrahim S, Sun Z, et al. Long noncoding antisense RNA KRT7-AS is activated in gastric cancers and supports cancer cell progression by increasing KRT7 expression. Oncogene. 2016; 35(37):4927-36.

84. Hatzoglou A, Deshayes F, Madry C, Lapree G, Castanas E, Tsapis A. Natural antisense RNA inhibits the expression of BCMA, a tumour necrosis factor receptor homologue. BMC Mol Biol. 2002;3:4.

85. Laabi Y, Gras MP, Brouet JC, Berger R, Larsen CJ, Tsapis A. The BCMA gene, preferentially expressed during $B$ lymphoid maturation, is bidirectionally transcribed. Nucleic Acids Res. 1994;22(7):1147-54.

86. Ebralidze AK, Guibal FC, Steidl U, Zhang P, Lee S, Bartholdy B, et al. PU.1 expression is modulated by the balance of functional sense and antisense RNAs regulated by a shared cis-regulatory element. Genes Dev. 2008;22(15): 2085-92.

87. Maruyama T, Nara K, Yoshikawa H, Suzuki N. Txk, a member of the non-receptor tyrosine kinase of the Tec family, forms a complex with poly(ADP-ribose) polymerase 1 and elongation factor 1alpha and regulates interferon-gamma gene transcription in Th1 cells. Clin Exp Immunol. 2007:147(1):164-75.

88. Bracken CP, Scott HS, Goodall GJ. A network-biology perspective of microRNA function and dysfunction in cancer. Nat Rev Genet. 2016;17(12): 719-32.

89. Liu G, Wang L, Han H, Li Y, Lu S, Li T, et al. LncRNA ZFAS1 promotes growth and metastasis by regulating BMI1 and ZEB2 in osteosarcoma. Am J Cancer Res. 2017;7(7):1450-62

90. Zhang W, Wu Y, Hou B, Wang Y, Deng D, Fu Z, et al. A SOX9-AS1/miR-55903p/SOX9 positive feedback loop drives tumor growth and metastasis in hepatocellular carcinoma through the Wnt/beta-catenin pathway. Molecular oncology. 2019;13(10):2194-210.

91. Takahashi H, Kozhuharova A, Sharma H, Hirose M, Ohyama T, Fasolo F, et al. Identification of functional features of synthetic SINEUPs, antisense IncRNAs that specifically enhance protein translation. PloS one. 2018;13(2):e0183229.

92. Carrieri C, Cimatti L, Biagioli M, Beugnet A, Zucchelli S, Fedele S, et al. Long non-coding antisense RNA controls Uchl1 translation through an embedded SINEB2 repeat. Nature. 2012;491(7424):454-7.

93. Schein A, Zucchelli S, Kauppinen S, Gustincich S, Carninci P. Identification of antisense long noncoding RNAs that function as SINEUPs in human cells. Sci Rep. 2016:6:33605

94. Chen L, Liu S, Tao Y. Regulating tumor suppressor genes: post-translational modifications. Signal Transduct Target Ther. 2020;5(1):90.

95. Fu T, Ji K, Jin L, Zhang J, Wu X, Ji X, et al. ASB16-AS1 up-regulated and phosphorylated TRIM37 to activate NF-kappaB pathway and promote proliferation, stemness, and cisplatin resistance of gastric cancer. Gastric 
Cancer. Online ahead of print at https://doi.org/10.1007/s10120-020-01096$y(2020)$.

96. Lotem J, Levanon D, Negreanu V, Bauer O, Hantisteanu S, Dicken J, et al. Runx3 in Immunity, Inflammation and Cancer. Adv Exp Med Biol. 2017;962 369-93

97. Zhuang X, Zhang H, Hu G. Cancer and Microenvironment Plasticity: DoubleEdged Swords in Metastasis. Trends Pharmacol Sci. 2019;40(6):419-29.

98. Hinshaw DC, Shevde LA. The Tumor Microenvironment Innately Modulates Cancer Progression. Cancer Res. 2019;79(18):4557-66.

99. Cheng J, Meng J, Zhu L, Peng Y. Exosomal noncoding RNAs in Glioma: biological functions and potential clinical applications. Mol Cancer. 2020; 19(1):66.

100. Poulet C, Njock MS, Moermans C, Louis E, Louis R, Malaise M, et al. Exosomal Long Non-Coding RNAs in Lung Diseases. Int J Mol Sci. 2020; 21(10):3580.

101. Bartonicek N, Maag JL, Dinger ME. Long noncoding RNAs in cancer: mechanisms of action and technological advancements. Mol Cancer. 2016; 15(1):43.

102. Gutschner T, Diederichs $\mathrm{S}$. The hallmarks of cancer: a long non-coding RNA point of view. RNA Biol. 2012;9(6):703-19.

103. Akl MR, Nagpal P, Ayoub NM, Tai B, Prabhu SA, Capac CM, et al. Molecular and clinical significance of fibroblast growth factor 2 (FGF2/bFGF) in malignancies of solid and hematological cancers for personalized therapies. Oncotarget. 2016;7(28):44735-62.

104. Duan H, Li X, Chen Y, Wang Y, Li Z. LncRNA RHPN1-AS1 promoted cell proliferation, invasion and migration in cervical cancer via the modulation of miR-299-3p/FGF2 axis. Life Sci. 2019;239:116856.

105. Liu J, Zhao SY, Jiang Q, Qu Y, Huang X, Du J, et al. Long noncoding RNA MYLK-AS1 promotes growth and invasion of hepatocellular carcinoma through the EGFR/HER2-ERK1/2 signaling pathway. Int J Biol Sci. 2020;16(11): 1989-2000.

106. McCarthy N. Tumour suppressors: Master weaver regulates guardian. Nat Rev Cancer. 2014;14(5):295.

107. Stracquadanio G, Wang X, Wallace MD, Grawenda AM, Zhang P, Hewitt J, et al. The importance of p53 pathway genetics in inherited and somatic cancer genomes. Nat Rev Cancer. 2016;16(4):251-65.

108. Mayo LD, Donner DB. The PTEN. Mdm2, p53 tumor suppressor-oncoprotein network. Trends Biochem Sci. 2002;27(9):462-7.

109. Wang H, Fang L, Jiang J, Kuang Y, Wang B, Shang X, et al. The cisplatininduced IncRNA PANDAR dictates the chemoresistance of ovarian cancer via regulating SFRS2-mediated p53 phosphorylation. Cell Death Dis. 2018; 9(11):1103.

110. Mahmoudi S, Henriksson S, Corcoran M, Mendez-Vidal C, Wiman KG, Farnebo M. Wrap53, a natural p53 antisense transcript required for p53 induction upon DNA damage. Mol Cell. 2009;33(4):462-71.

111. Blasco MA. Telomeres and human disease: ageing, cancer and beyond. Nat Rev Genet. 2005;6(8):611-22.

112. Xu L, Li S, Stohr BA. The role of telomere biology in cancer. Annu Rev Pathol. 2013:8:49-78

113. Liu X, Fu Q, Li S, Liang N, Li F, Li C, et al. LncRNA FOXD2-AS1 Functions as a Competing Endogenous RNA to Regulate TERT Expression by Sponging miR-7-5p in Thyroid Cancer. Front Endocrinol. 2019;10:207.

114. Malhotra S, Freeberg MA, Winans SJ, Taylor J, Beemon KL. A Novel Long Non-Coding RNA in the hTERT Promoter Region Regulates hTERT Expression. Non-coding RNA. 2017:4(1):1.

115. Apel A, Zentgraf H, Buchler MW, Herr I. Autophagy-A double-edged sword in oncology. International journal of cancer. 2009;125(5):991-5.

116. Tompkins KD, Thorburn A. Regulation of Apoptosis by Autophagy to Enhance Cancer Therapy. Yale J Biol Med. 2019:92(4):707-18.

117. Zhao GX, Pan H, Ouyang DY, He XH. The critical molecular interconnections in regulating apoptosis and autophagy. Annals of medicine. 2015:47(4):305-15.

118. Porta C, Paglino C, Mosca A. Targeting PI3K/Akt/mTOR Signaling in Cancer. Front Oncol. 2014:4:64

119. Li Z, Qian J, Li J, Zhu C. Knockdown of IncRNA-HOTAIR downregulates the drug-resistance of breast cancer cells to doxorubicin via the PI3K/AKT/mTOR signaling pathway. Exp Ther Med. 2019;18(1):435-42.

120. Liu G, Zhao X, Zhou J, Cheng X, Ye Z, Ji Z. LncRNA TP73-AS1 Promotes Cell Proliferation and Inhibits Cell Apoptosis in Clear Cell Renal Cell Carcinoma Through Repressing KISS1 Expression and Inactivation of PI3K/Akt/mTOR Signaling Pathway. Cell Physiol Biochem. 2018;48(1):371-84.
121. Zheng $Y$, Tan $K$, Huang H. Long noncoding RNA HAGLROS regulates apoptosis and autophagy in colorectal cancer cells via sponging miR-100 to target ATG5 expression. J Cell Biochem. 2019;120(3):3922-33.

122. Kalluri R, Weinberg RA. The basics of epithelial-mesenchymal transition. J Clin Invest. 2009;119(6):1420-8.

123. Fouad YA, Aanei C. Revisiting the hallmarks of cancer. Am J Cancer Res. 2017;7(5):1016-36

124. Berx G, van Roy F. Involvement of members of the cadherin superfamily in cancer. Cold Spring Harb Perspect Biol. 2009;1(6):a003129.

125. Song Y, Wang R, Li LW, Liu X, Wang YF, Wang QX, et al. Long non-coding RNA HOTAIR mediates the switching of histone H3 lysine 27 acetylation to methylation to promote epithelial-to-mesenchymal transition in gastric cancer. Int J Oncol. 2019;54(1):77-86.

126. Geng YJ, Xie SL, Li Q, Ma J, Wang GY. Large intervening non-coding RNA HOTAIR is associated with hepatocellular carcinoma progression. J Int Med Res. 2011;39(6):2119-28.

127. Bourboulia D, Stetler-Stevenson WG. Matrix metalloproteinases (MMPs) and tissue inhibitors of metalloproteinases (TIMPs): Positive and negative regulators in tumor cell adhesion. Sem Cancer Biol. 2010;20(3):161-8.

128. Xia H, Jing H, Li Y, Lv X. Long noncoding RNA HOXD-AS1 promotes nonsmall cell lung cancer migration and invasion through regulating miR-133b/ MMP9 axis. Biomed Pharmacother. 2018;106:156-62.

129. Wang $X$, Yang B, She Y, Ye Y. The IncRNA TP73-AS1 promotes ovarian cancer cell proliferation and metastasis via modulation of MMP2 and MMP9. J Cell Biochem. 2018;1 19(9):7790-9.

130. Hanahan D, Folkman J. Patterns and emerging mechanisms of the angiogenic switch during tumorigenesis. Cell. 1996;86(3):353-64.

131. Khorshidi A, Dhaliwal P, Yang BB. Noncoding RNAs in Tumor Angiogenesis. Adv Exp Med Biol. 2016:927:217-41.

132. Qian CN, Tan MH, Yang JP, Cao Y. Revisiting tumor angiogenesis: vessel cooption, vessel remodeling, and cancer cell-derived vasculature formation. Chin J Cancer. 2016:35:10.

133. Ramjiawan RR, Griffioen AW, Duda DG. Anti-angiogenesis for cancer revisited: Is there a role for combinations with immunotherapy? Angiogenesis. 2017;20(2):185-204.

134. Rossignol F, Vache C, Clottes E. Natural antisense transcripts of hypoxiainducible factor 1alpha are detected in different normal and tumour human tissues. Gene. 2002:299(1-2):135-40.

135. Uchida T, Rossignol F, Matthay MA, Mounier R, Couette S, Clottes E, et al. Prolonged hypoxia differentially regulates hypoxia-inducible factor (HIF)1alpha and HIF-2alpha expression in lung epithelial cells: implication of natural antisense HIF-1alpha. J Biol Chem. 2004;279(15):14871-8.

136. Lu T, Tang J, Shrestha B, Heath BR, Hong L, Lei YL, et al. Up-regulation of hypoxia-inducible factor antisense as a novel approach to treat ovarian cancer. Theranostics. 2020;10(15):6959-76.

137. Guo X, Lee S, Cao P. The inhibitive effect of sh-HIF1A-AS2 on the proliferation, invasion, and pathological damage of breast cancer via targeting miR-548c-3p through regulating HIF-1alpha/NEGF pathway in vitro and vivo. Onco Targets Ther. 2019;12:825-34.

138. Chen X, Liu M, Meng F, Sun B, Jin X, Jia C. The long noncoding RNA HIF1AAS2 facilitates cisplatin resistance in bladder cancer. J Cell Biochem. 2019; 120(1):243-52.

139. Chen X, Zeng K, Xu M, Hu X, Liu X, Xu T, et al. SP1-induced IncRNA-ZFAS1 contributes to colorectal cancer progression via the miR-150-5p/NEGFA axis. Cell Death Dis. 2018;9(10):982.

140. Zhu G, Wang S, Chen J, Wang Z, Liang X, Wang X, et al. Long noncoding RNA HAS2-AS1 mediates hypoxia-induced invasiveness of oral squamous cell carcinoma. Mol Carcinog. 2017;56(10):2210-22.

141. Maciejowski J, de Lange T. Telomeres in cancer: tumour suppression and genome instability. Nat Rev Mol Cell Biol. 2017;18(3):175-86.

142. Maciejowski J, Li Y, Bosco N, Campbell PJ, de Lange T. Chromothripsis and Kataegis Induced by Telomere Crisis. Cell. 2015;163(7):1641-54.

143. Artandi SE, DePinho RA. Telomeres and telomerase in cancer. Carcinogenesis. 2010;31(1):9-18.

144. Gachechiladze M, Skarda J, Soltermann A, Joerger M. RAD51 as a potential surrogate marker for DNA repair capacity in solid malignancies. Int I Cancer. 2017;141(7):1286-94

145. Chen CC, Chen CY, Ueng SH, Hsueh C, Yeh CT, Ho JY, et al. Corylin increases the sensitivity of hepatocellular carcinoma cells to chemotherapy through long noncoding RNA RAD51-AS1-mediated inhibition of DNA repair. Cell Death Dis. 2018;9(5):543. 
146. Li J, Ji X, Wang H. Targeting Long Noncoding RNA HMMR-AS1 Suppresses and Radiosensitizes Glioblastoma. Neoplasia. 2018;20(5):456-66.

147. Henriksson S, Rassoolzadeh H, Hedstrom E, Coucoravas C, Julner A, Goldstein $\mathrm{M}$, et al. The scaffold protein WRAP53beta orchestrates the ubiquitin response critical for DNA double-strand break repair. Genes Dev. 2014;28(24):2726-38

148. Peng J, Zhan Y, Feng J, Fan S, Zang H. Expression of WDR79 is associated with TP53 mutation and poor prognosis in surgically resected non-small cell lung cancer. J Cancer. 2019;10(13):3046-53.

149. Alves-Fernandes DK, Jasiulionis MG. The Role of SIRT1 on DNA Damage Response and Epigenetic Alterations in Cancer. Int J Mol Sci. 2019;20(13): 3153.

150. Choupani J, Mansoori Derakhshan S, Bayat S, Alivand MR, Shekari Khaniani M. Narrower insight to SIRT1 role in cancer: A potential therapeutic target to control epithelial-mesenchymal transition in cancer cells. J Cell Physiol. 2018;233(6):4443-57.

151. Liu J, Wu W, Jin J. A novel mutation in SIRT1-AS leading to a decreased risk of HCC. Oncol Rep. 2015;34(5):2343-50.

152. Baxevanis CN, Fortis SP, Perez SA. The balance between breast cancer and the immune system: Challenges for prognosis and clinical benefit from immunotherapies. Semin Cancer Biol. Online ahead of print at https://doi. org/10.1016/j.semcancer.2019.12.018(2019).

153. Fan L, Li Y, Chen JY, Zheng YF, Xu XM. Immune checkpoint modulators in cancer immunotherapy: Recent advances and combination rationales. Cancer Lett. 2019;456:23-8.

154. Kathuria H, Millien G, McNally L, Gower AC, Tagne JB, Cao Y, et al. NKX2-1AS1 negatively regulates CD274/PD-L1, cell-cell interaction genes, and limits human lung carcinoma cell migration. Sci Rep. 2018;8(1):14418.

155. Tang Y, He Y, Shi L, Yang L, Wang J, Lian Y, et al. Co-expression of AFAP1AS1 and PD-1 predicts poor prognosis in nasopharyngeal carcinoma. Oncotarget. 2017:8(24):39001-11.

156. Greten FR, Grivennikov SI. Inflammation and Cancer: Triggers, Mechanisms, and Consequences. Immunity. 2019;51(1):27-41.

157. Grivennikov SI, Greten FR, Karin M. Immunity, inflammation, and cancer. Cell. 2010;140(6):883-99.

158. Gupta SC, Kunnumakkara AB, Aggarwal S, Aggarwal BB. Inflammation, a Double-Edge Sword for Cancer and Other Age-Related Diseases. Front Immunol. 2018;9:2160

159. Mantovani A, Allavena P, Sica A, Balkwill F. Cancer-related inflammation. Nature. 2008:454(7203):436-44

160. Ritter B, Greten FR. Modulating inflammation for cancer therapy. J Exp Med. 2019;216(6):1234-43

161. Yu H, Pardoll D, Jove R. STATs in cancer inflammation and immunity: a leading role for STAT3. Nat Rev Cancer. 2009;9(11):798-809.

162. Ji Z, He L, Regev A, Struhl K. Inflammatory regulatory network mediated by the joint action of NF-kB, STAT3, and AP-1 factors is involved in many human cancers. Proc Natl Acad Sci U S A. 2019;116(19):9453-62.

163. Fan Y, Mao R, Yang J. NF-kappaB and STAT3 signaling pathways collaboratively link inflammation to cancer. Protein Cell. 2013;4(3):176-85.

164. Johnson DE, O'Keefe RA, Grandis JR. Targeting the IL-6/JAK/STAT3 signalling axis in cancer. Nat Rev Clin Oncol. 2018;15(4):234-48.

165. Ozes AR, Miller DF, Ozes ON, Fang F, Liu Y, Matei D, et al. NF-kappaBHOTAIR axis links DNA damage response, chemoresistance and cellular senescence in ovarian cancer. Oncogene. 2016;35(41):5350-61.

166. Liu B, Liu Q, Pan S, Huang Y, Qi Y, Li S, et al. The HOTAIR/miR-214/ ST6GAL1 crosstalk modulates colorectal cancer procession through mediating sialylated c-Met via JAK2/STAT3 cascade. J Exp Clin Cancer Res. 2019;38(1):455.

167. Wang $N$, Jiang $Y$, Lv S, Wen $H$, Wu D, Wei Q, et al. HOTAIR expands the population of prostatic cancer stem-like cells and causes Docetaxel resistance via activating STAT3 signaling. Aging. 2020;12(13):12771-82.

168. Wang S, Zhang S, He Y, Huang X, Hui Y, Tang Y. HOXA11-AS regulates JAKSTAT pathway by miR-15a-3p/STAT3 axis to promote the growth and metastasis in liver cancer. J Cell Biochem. 2019;120(9):15941-51.

169. Liang C, Zhao T, Li H, He F, Zhao X, Zhang Y, et al. Long Non-coding RNA ITIH4-AS1 Accelerates the Proliferation and Metastasis of Colorectal Cancer by Activating JAK/STAT3 Signaling. Mol Ther Nucleic Acids. 2019;18:183-93.

170. Warburg O. On the origin of cancer cells. Science. 1956;123(3191):309-14.

171. Warburg O. The Chemical Constitution of Respiration Ferment. Science. 1928;68(1767):437-43.
172. DeBerardinis RJ, Chandel NS. Fundamentals of cancer metabolism. Sci Adv. 2016;2(5):e1600200.

173. Peppicelli S, Bianchini F, Calorini L. Extracellular acidity, a "reappreciated" trait of tumor environment driving malignancy: perspectives in diagnosis and therapy. Cancer Metastasis Rev. 2014;33(2-3):823-32.

174. Dong Y, Tu R, Liu H, Qing G. Regulation of cancer cell metabolism: oncogenic MYC in the driver's seat. Signal Transduct Target Ther. 2020;5(1): 124.

175. Al Tameemi W, Dale TP, Al-Jumaily RMK, Forsyth NR. Hypoxia-Modified Cancer Cell Metabolism. Front Cell Dev Biol. 2019;7:4.

176. Xiang S, Gu H, Jin L, Thorne RF, Zhang XD, Wu M. LncRNA IDH1-AS1 links the functions of c-Myc and HIF1alpha via IDH1 to regulate the Warburg effect. Proc Natl Acad Sci U S A. 2018;115(7):E1465-E74.

177. Zhang S, Guan Y, Liu X, Ju M, Zhang Q. Long non-coding RNA DLEU1 exerts an oncogenic function in non-small cell lung cancer. Biomed Pharmacother. 2019;109:985-90.

178. Modarresi F, Faghihi MA, Lopez-Toledano MA, Fatemi RP, Magistri M, Brothers SP, et al. Inhibition of natural antisense transcripts in vivo results in gene-specific transcriptional upregulation. Nat Biotechnol. 2012;30(5):453-9.

179. Derrien T, Johnson R, Bussotti G, Tanzer A, Djebali S, Tilgner H, et al. The GENCODE v7 catalog of human long noncoding RNAs: analysis of their gene structure, evolution, and expression. Genome Res. 2012;22(9):1775-89.

180. Arun G, Diermeier SD, Spector DL. Therapeutic Targeting of Long NonCoding RNAs in Cancer. Trends Mol Med. 2018;24(3):257-77.

181. Goyal A, Myacheva K, Gross M, Klingenberg M, Duran Arque B, Diederichs S. Challenges of CRISPR/Cas9 applications for long non-coding RNA genes. Nucleic Acids Res. 2017;45(3):e12.

182. Howe FS, Russell A, Lamstaes AR, El-Sagheer A, Nair A, Brown T, et al. CRISPRi is not strand-specific at all loci and redefines the transcriptional landscape. Elife. 2017;6:e29878.

183. Evers B, Jastrzebski K, Heijmans JP, Grernrum W, Beijersbergen RL, Bernards R. CRISPR knockout screening outperforms shRNA and CRISPRi in identifying essential genes. Nat Biotechnol. 2016;34(6):631-3.

184. Jiang MC, Ni JJ, Cui WY, Wang BY, Zhuo W. Emerging roles of IncRNA in cancer and therapeutic opportunities. Am J Cancer Res. 2019;9(7):1354-66.

185. Liu J, Ben Q, Lu E, He X, Yang X, Ma J, et al. Long noncoding RNA PANDAR blocks CDKN1A gene transcription by competitive interaction with p53 protein in gastric cancer. Cell Death Dis. 2018;9(2):168.

186. Wahlestedt C. Targeting long non-coding RNA to therapeutically upregulate gene expression. Nat Rev Drug Discov. 2013;12(6):433-46.

187. Su JC, Hu XF. Long noncoding RNA HOXA11AS promotes cell proliferation and metastasis in human breast cancer. Mol Med Rep. 2017;16(4):4887-94.

188. Huang Y, Chen R, Zhou J. E2F1 and NF-kappaB: Key Mediators of Inflammation-associated Cancers and Potential Therapeutic Targets. Curr Cancer Drug Targets. 2016;16(9):765-72.

189. Denechaud PD, Fajas L, Giralt A. E2F1, a Novel Regulator of Metabolism. Front Endocrinol. 2017;8:311.

190. Santoro F, Pauler FM. Silencing by the imprinted Airn macro IncRNA: transcription is the answer. Cell cycle. 2013;12(5):711-2.

191. Zhang G, Li H, Sun R, Li P, Yang Z, Liu Y, et al. Long non-coding RNA ZEB2AS1 promotes the proliferation, metastasis and epithelial mesenchymal transition in triple-negative breast cancer by epigenetically activating ZEB2. J Cell Mol Med. 2019;23(5):3271-9.

192. Cho SF, Lin L, Xing L, Li Y, Yu T, Anderson KC, et al. BCMA-Targeting Therapy: Driving a New Era of Immunotherapy in Multiple Myeloma. Cancers. 2020;12(6):1473.

193. Burda P, Laslo P, Stopka T. The role of PU.1 and GATA-1 transcription factors during normal and leukemogenic hematopoiesis. Leukemia. 2010;24(7):1249-57.

\section{Publisher's Note}

Springer Nature remains neutral with regard to jurisdictional claims in published maps and institutional affiliations. 